\title{
Article \\ Ordered Nanostructure Catalysts Efficient for NOx Storage/Reduction (NSR) Processes
}

\author{
Shuichi Naito
}

Citation: Naito, S. Ordered Nanostructure Catalysts Efficient for NOx Storage/Reduction (NSR) Processes. Catalysts 2021, 11, 1348. https://doi.org/10.3390/ catal11111348

Academic Editor: Young-Kwon Park

Received: 12 October 2021

Accepted: 4 November 2021

Published: 9 November 2021

Publisher's Note: MDPI stays neutral with regard to jurisdictional claims in published maps and institutional affiliations.

Copyright: (C) 2021 by the author. Licensee MDPI, Basel, Switzerland. This article is an open access article distributed under the terms and conditions of the Creative Commons Attribution (CC BY) license (https:/ / creativecommons.org/licenses/by/ $4.0 /)$.
Department of Material \& Life Chemistry, Faculty of Engineering, Kanagawa University, Rokkakubashi, Kanagawa-ku, Yokohama 221-8686, Japan; naitos01@kanagawa-u.ac.jp

\begin{abstract}
NOx emissions in the atmosphere can cause various environmental problems, which should be strictly controlled and regulated. Furthermore, because of the limited amount of crude oil resources in the world and severe global warming, the development of fuel-efficient vehicles has long been desired. Accordingly, efficient NOx storage and reduction catalysts have been developed over the decades, called NSR (NOx storage/reduction) catalysts. In the present article, recent advances in NSR catalysts which possess ordered nanostructures will be summarized, including our noble $\mathrm{Pt} / \mathrm{KNO}_{3} / \mathrm{K}$-titanate nanobelt $(\mathrm{KTN}), \mathrm{Pt}-\mathrm{KNO}_{3} / \mathrm{CeO}_{2}$ and $\mathrm{Pt}-\mathrm{KNO}_{3} / \mathrm{ZrO}_{2}$ catalysts, as well as nanoporous Ni-phosphate (VSB-5) and Co-substituted VSB-5 catalysts.
\end{abstract}

Keywords: NOx storage; ordered nanostructure catalyst; NSR process; K-titanate nanobelt; VSB-5

\section{Introduction}

\subsection{Overview of the Development on NSR Catalysts}

Emissions of $\mathrm{NO}_{x}$ in the atmosphere can cause various environmental problems. Therefore, it is an urgent requirement that $\mathrm{NO}_{x}$ emissions should be strictly controlled and regulated [1]. On the other hand, due to the limited quantity of raw oil resources in the world and seriously increasing global warming, fuel-efficient vehicles become desirable. Most current gasoline-burning engines are operating with a very narrow air-to-fuel ratio $(\mathrm{A} / \mathrm{F})$ range near the stoichiometric value $\left(\mathrm{A} / \mathrm{F}=14.7\right.$, rich-burn) with little or no $\mathrm{O}_{2}$ in the exhaust, while lean-burn engines $(\mathrm{A} / \mathrm{F}=20-25)$ can burn fuel more efficiently $[2,3]$. However, the conventional three-way catalyst is no longer effective for $\mathrm{NO}_{\mathrm{x}}$ removal in an oxidative atmosphere. Therefore, an effective $\mathrm{NO}_{\mathrm{x}}$ removal method for lean-burn exhaust becomes desirable from the environmental and catalytic point of view. $\mathrm{NO}_{\mathrm{x}}$ removal technologies under the lean-burn condition include direct catalytic decomposition of $\mathrm{NO}_{\mathrm{x}}$ catalytic $\mathrm{NO}_{x}$ storage/reduction (NSR) [1,4-7], and selective catalytic reduction of $\mathrm{NO}_{x}$ with urea/ $\mathrm{NH}_{3}[8,9]$ or hydrocarbons [10-12].

The NSR catalysts operate under cyclic fuel lean-rich conditions. Under the lean-burn condition, $\mathrm{NO}_{\mathrm{x}}$ is absorbed onto the catalyst, and under the rich-burn condition, stored $\mathrm{NO}_{x}$ is reduced by $\mathrm{H}_{2}, \mathrm{CO}$, and hydrocarbons. In real systems, a storage period of 1-2 min, followed by $3-5 \mathrm{sec}$ of rich conditions, is typically adopted. To achieve this cycle, NSR catalysts are composed of three essential elements: (1) a high-surface-area metal oxide, such as $\mathrm{Al}_{2} \mathrm{O}_{3}$, as a support; (2) basic elements, such as $\mathrm{Ba}$ or $\mathrm{K}$, for the $\mathrm{NO}_{\mathrm{x}}$ storage sites; and (3) precious-metal redox sites, such as $\mathrm{Pt}, \mathrm{Pd}$, and $\mathrm{Rh}$, for the redox reaction for oxidizing $\mathrm{NO}$ to $\mathrm{NO}_{2}$ and reducing stored $\mathrm{NO}_{x}$ to $\mathrm{N}_{2}$ by various reductants. Typical model of an NSR catalyst is $\mathrm{Pt}-\mathrm{Ba} / \mathrm{Al}_{2} \mathrm{O}_{3}$, which was developed by Toyota's research group [6-9]. Although considerable amounts of experimental and theoretical investigations of $\mathrm{Pt}-\mathrm{Ba} / \mathrm{Al}_{2} \mathrm{O}_{3}$ have been conducted, serious problems still remain with respect to sulfur poisoning [6,13-16]. Meanwhile, high- $\mathrm{NO}_{x}$ storage NSR catalysts are desirable because increasing $\mathrm{NO}_{x}$ storage capacity can decrease the necessary catalyst and, in turn, decrease the amount of precious metals required and the cost. 


\subsection{Application of Nanotechnology for NSR Processes}

In order to obtain better NSR catalysts, the application of nanotechnology seems to be promising. As for support materials other than $\mathrm{Al}_{2} \mathrm{O}_{3}$, titanium dioxide has been proposed as an efficient support since it has a relatively higher resistance to sulfur poisoning [6]. Previous reports have demonstrated that K-based catalysts showed good performance in $\mathrm{NO}_{\mathrm{x}}$ storage in lean-burn atmospheres [15-20]. Most researchers believe that the reaction of $\mathrm{K}$ and $\mathrm{TiO}_{2}$ will cause the loss of $\mathrm{NO}_{\mathrm{x}}$ storage capacity. However, recent studies on $\mathrm{K}_{2} \mathrm{Ti}_{2} \mathrm{O}_{5}$ prepared by a solid-state reaction showed high $\mathrm{NO}_{\mathrm{x}}$ storage capacity $(1.2 \mathrm{mmol} / \mathrm{g})$ at $550{ }^{\circ} \mathrm{C}[21,22]$. The structural transformation between $\mathrm{K}_{2} \mathrm{Ti}_{2} \mathrm{O}_{5}$ and $\mathrm{K}_{2} \mathrm{Ti}_{6} \mathrm{O}_{13}$ was considered as the mechanism for $\mathrm{NO}_{x}$ storage in $\mathrm{Pt} / \mathrm{K}_{2} \mathrm{Ti}_{2} \mathrm{O}_{5}$ [22]. The lower $\mathrm{NO}_{x}$ storage capacity at relatively lower temperature $\left(200-400{ }^{\circ} \mathrm{C}\right)$ and the slower $\mathrm{NO}_{\mathrm{x}}$ storage rate even at higher temperatures $\left(550^{\circ} \mathrm{C}\right)$ have resulted in the limited application of $\mathrm{K}_{2} \mathrm{Ti}_{2} \mathrm{O}_{5}$-based catalysts.

Alkali-titanate nanomaterials have been widely investigated [23-27]; however, the usual applications have directed the formation of functional materials by neutralizing them with acid [28-30]. Recently, we reported on the preparation of potassium-titanate nanobelts (KTN) with the hydrothermal method and employed them as supports for Pt- $\mathrm{KNO}_{3}$-impregnated NSR catalysts [31]. The obtained catalysts exhibited a high $\mathrm{NO}_{x}$ storage capacity $(1.27-2.27 \mathrm{mmol} / \mathrm{g})$ at $350{ }^{\circ} \mathrm{C}$, the maximal value of which $(2.27 \mathrm{mmol})$ was the highest $\mathrm{NO}_{\mathrm{x}}$ storage capacity ever reported in the relevant literature. From the results of isothermal $\mathrm{NO}_{x}$ storage and lean-rich cycling experiments, as well as various characterizations of catalysts before and after the reaction, we were able to demonstrate that the reduction of stored $\mathrm{KNO}_{3}$ resulted from the formation of K-rich surface layers of KTN [32]. The migration of $\mathrm{K}^{+}$from and back to the K-rich layer might be the mechanism for the storage and reduction of $\mathrm{NO}_{x}$ in those catalysts, which will be discussed deeply in this paper. We also compared NSR behaviors of various alkali-metal-nitrate-impregnated KTN catalysts and found that the $\mathrm{KNO}_{3}$-impregnated catalyst showed the best performance. The XPS and XRD analyses of $\mathrm{NaNO}_{3}$-impregnated Pt/KTN catalysts revealed that the migration of $\mathrm{K}^{+}$from KTN bulk to the surface nitrate salts proceeds more predominantly than the migration of $\mathrm{Na}^{+}$, which could be the reason why $\mathrm{KNO}_{3}$-impregnated KTN exhibited the best catalytic performance. We have extended our study to $\mathrm{CeO}_{2}$ and $\mathrm{ZrO}_{2}$ supports since they have unique catalytic behavior for oxygen transfer and storage, and we investigate NSR behavior of $\mathrm{Pt}-\mathrm{K} / \mathrm{CeO}_{2}$ and $\mathrm{Pt}-\mathrm{K} / \mathrm{ZrO}_{2}$ catalysts in this article.

Since NO is one of the main atmospheric pollutants that can cause acid rain, photochemical smog, depletion of stratospheric ozone, and greenhouse effects, the removal of NO has been one of the hottest topics around the world. Great efforts have been focused on the exploitation of novel kinds of catalysts to realize practical applications or to illuminate the reaction mechanism for NSR processes [33,34]. Among various proposed catalysts, ion-exchanged zeolites have shown particularly high catalytic activities for NSR processes, which presenting high catalytic performance at low temperatures [35-37]. Additionally, notable attention has been concentrated on the fundamental studies of the mechanism of the process by using in situ FT-IR, XPS, TPD, and so on. A significant amount of fundamental research using supported noble or transition-metal catalysts has been carried out to study the nature of catalytic removal of $\mathrm{NO}$ by $\mathrm{H}_{2}$ or $\mathrm{CO}$ [38-40]. Transition-metalcontaining zeolites are the most promising SCR catalysts due to their high performance in selective catalytic reduction of nitrogen oxides by hydrocarbons on Ni-ZSM-5 and Co-ZSM-5, etc. [41-43]. In these reports, NO and CO have been employed as the probe molecule to monitor the surface of transition-metal ions [41]. The adsorbed species with high stability have been identified as intermediates contributing to the catalytic efficiency. IR spectroscopy, especially in situ IR, provides significant information about the nature of the bonds formed between the surface of catalysts and adsorbates [43-46].

Several years ago, we used nanoporous nickel phosphate VSB-5 for the first time as the active component for $\mathrm{NO}$ and $\mathrm{CO}$ adsorption [47]. To the best of our knowledge, it was the first time that nickel was used as a catalyst with all nickel ions located in the framework for 
the reaction, which is different from $\mathrm{Ni}$ species in ion-exchanged zeolites. Nickel phosphate VSB-5 (Versailles-Santa Barbara) is a nanoporous material with a 24-ringopen framework and high thermal stability [15]. In contrast to traditional aluminosilicate zeolites, VSB-5 has 1-D channels with a larger pore size of $1.1 \mathrm{~nm}$, and can realize the construction of nanostructure or can be a pathway for large molecules. Additionally, the different valences and various coordination numbers of the nickel ions make VSB-5 one of the most promising materials for a wide range of applications. For example, the unsaturated $\mathrm{Ni}^{2+}$ coordinate sites in the framework of VSB- 5 are accessible to $\mathrm{H}_{2}$ molecules in the pores, making VSB-5 one of the best candidates for hydrogen storage material in comparison with ZSM- 5 and active carbon. However, although more and more attention has been focused on VSB- 5 , the understanding of active, unsaturated $\mathrm{Ni}^{2+}$ sites is not clear yet, which may hinder the further application of VSB-5 materials. Additionally, to the best of our knowledge, the use of NO or CO as probe molecules for investigating active sites in the pores of VSB-5 has never been reported, which may also benefit the application of VSB-5 in the de-NOx process.

\section{Results and Discussion}

\subsection{NSR Behavior over Various Nano Structured Catalysts}

2.1.1. Potassium Cation Transfer Mechanism in $\mathrm{NO}_{\mathrm{x}}$ Storage and Reduction Processes over $\mathrm{Pt} / \mathrm{K}$-Titania Nanobelt Catalysts

Since the pioneering work of $\mathrm{NO}_{\mathrm{x}}$ storage-reduction (NSR) catalysts by Toyota's research group, many studies have been reported on the mechanism of NSR reaction over $\mathrm{Pt}-\mathrm{BaO} / \mathrm{Al}_{2} \mathrm{O}_{3}$ catalysts. It is generally accepted that oxidation of $\mathrm{NO}$ to $\mathrm{NO}_{2}$ over $\mathrm{Pt}$ is a necessary initial step before $\mathrm{NO}_{\mathrm{x}}$ storage can take place over $\mathrm{BaO}$, forming $\mathrm{Ba}\left(\mathrm{NO}_{3}\right)_{2}$ surface layers on the bulk $\mathrm{BaO}$ particles. Recently, we have found that a $\mathrm{Pt} / \mathrm{KNO}_{3} / \mathrm{K}$ titanate nanobelt $(\mathrm{KTN})$ catalyst has the highest $\mathrm{NO}_{\mathrm{x}}$ storage capacity $(2.3 \mathrm{mmol} / \mathrm{g}$-cat $)$ among those reported in the literature, with excellent NSR performance. We have studied the mechanism of this NSR process by kinetic measurements, in situ XRD, TEM, XPS, and FT-IR measurements during the reaction and found that the main $\mathrm{NO}_{\mathrm{x}}$ storage phase was a $\mathrm{KNO}_{3}$-like composition, which transformed into K-rich surface layers of KTN in the reduction process. A novel "K cation transfer mechanism" was proposed from and back to K-rich titanate surface layers during storage-reduction cycles.

Figure 1 is the TEM image of the $\mathrm{Pt} / 20 \mathrm{wt} \% \mathrm{KTN}$ catalyst after $\mathrm{H}_{2}$ reduction, which was a needlelike nanobelt structure several $\mu \mathrm{m}$ in length and a few $\mathrm{nm}$ in width. The Pt metal particles were highly dispersed on all the catalysts, with the particle sizes around 1-2 nm. The nanobelt structure was maintained completely up to $26-33 \mathrm{wt} \% \mathrm{KNO}_{3}$ loading after the reaction. However, most of the nanobelts were destroyed on spent $\mathrm{Pt} / 41 \mathrm{wt} \% \mathrm{KNO}_{3} / \mathrm{KTN}$. Combining the results of isothermal $\mathrm{NO}_{\mathrm{x}}$ storage experiment and TEM observation, it is concluded that preservation of the nanobelt structure, as well as the addition of suitable amounts of $\mathrm{KNO}_{3}$, were the key factors to obtain high $\mathrm{NO}_{\mathrm{x}}$ storage capacity.

Time courses of isothermal $\mathrm{NO}_{x}$ storage are shown in Figure 2 over varied catalysts at $350{ }^{\circ} \mathrm{C}$. The storage process includes two stages: at the first stage, the $\mathrm{NO}_{\mathrm{x}}$ was completely trapped, no outlet $\mathrm{NO}$ being detected; at the second stage, $\mathrm{NO}_{\mathrm{x}}$ was partially trapped, the outlet NO being increased concomitantly with time. The time for the complete NOx absorption stage was elongated with the increase in added $\mathrm{KNO}_{3}$ until $33 \mathrm{wt} \%$ and then shortened. No other nitrogen species, such as $\mathrm{NO}_{2}$ and $\mathrm{N}_{2} \mathrm{O}$, were detected during these processes. Therefore, the total amount of NOx was estimated from this area, which is called QMS estimation. 


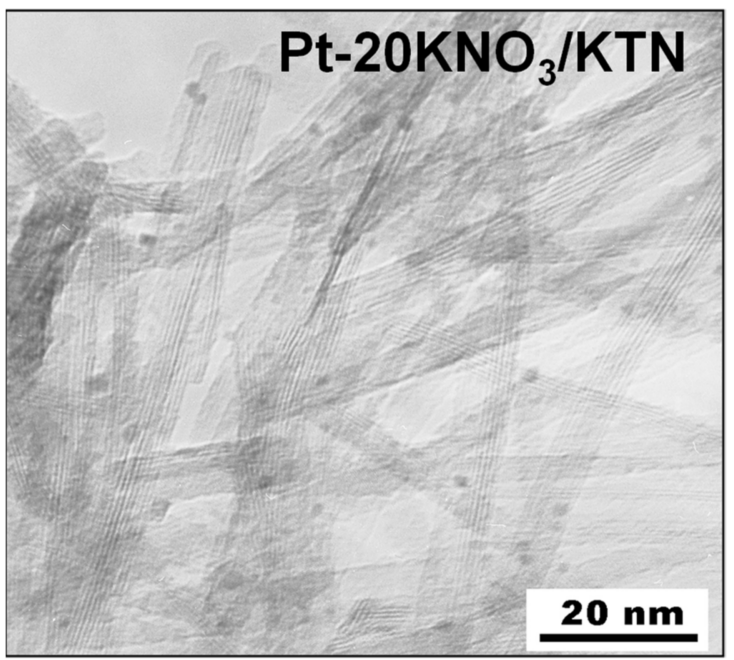

Figure 1. TEM photo of $\mathrm{Pt} / 20 \mathrm{wt} \% \mathrm{KTN}$.

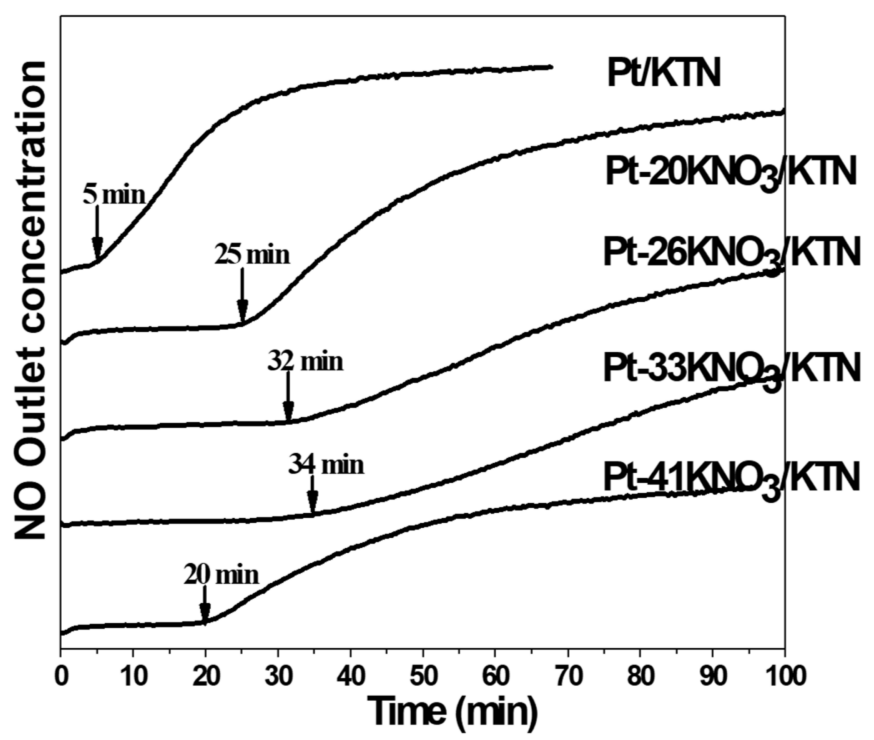

Figure 2. Time course of isothermal $\mathrm{NO}$ storage at $350{ }^{\circ} \mathrm{C}$.

Figure 3 shows the dependence of the $\mathrm{NO}_{\mathrm{x}}$ storage capacity upon the added amount of $\mathrm{KNO}_{3}$ on $\mathrm{KTN}$. The highest storage capacity of $2.27 \mathrm{mmol} / \mathrm{g}$ was achieved when $33 \mathrm{wt} \% \mathrm{KNO}_{3}$ was added to Pt/KTN. TEM images showed that the nanobelt structure was completely maintained even after the redox cycle, when the amount of modified $\mathrm{KNO}_{3}$ was lower than $26 \mathrm{wt} \%$. However, a small amount of nanobelt was collapsed to amorphous potassium-titanate particles after reaction over $\mathrm{Pt} / 33 \% \mathrm{KNO}_{3} / \mathrm{KTN}$, and most of the nanobelt was transformed into an amorphous form in the case of $\mathrm{Pt} / 41 \% \mathrm{KNO}_{3} / \mathrm{KTN}$. Accordingly, optimization of the amount of added $\mathrm{KNO}_{3}$ is the key factor to keep the nanobelt structure, as well as to obtain higher $\mathrm{NO}_{\mathrm{x}}$ storage capacity. 


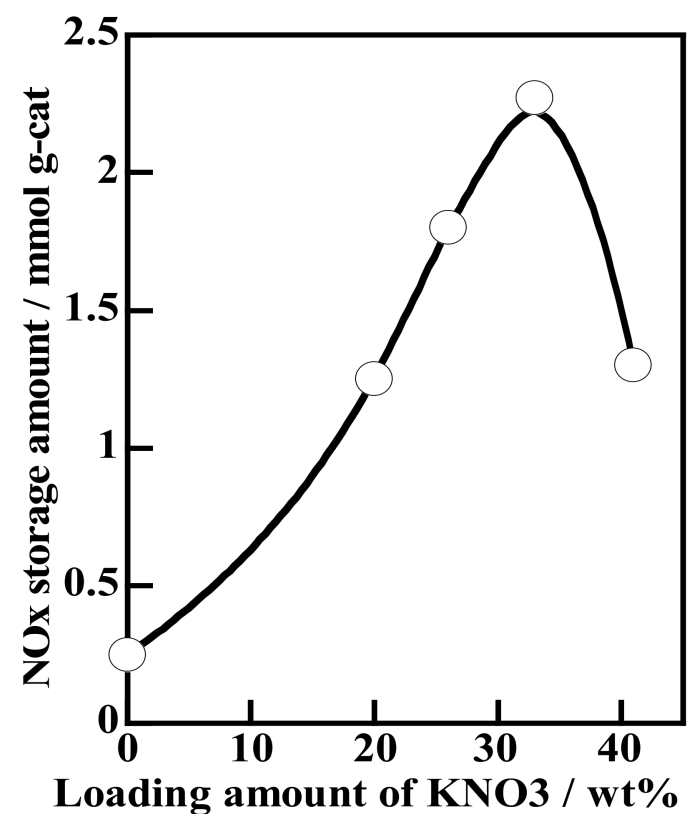

Figure 3. $\mathrm{KNO}_{3}$ loading dependency.

To more deeply evaluate the $\mathrm{NO}_{\mathrm{x}}$ storage and reduction rates, as well as the stability of the catalysts, lean-rich cycling tests were conducted, as shown in Figure 4, under 6 min storage and 4 min reduction cycles. During the $\mathrm{NO}_{\mathrm{x}}$ storage process, no $\mathrm{NO}$ was detected within 6 min, while when the gas flow was switched to $\mathrm{H}_{2}$, only $\mathrm{N}_{2}$ was detected as $\mathrm{N}$ species during reduction cycle, indicating the excellent NOx trapping capacity with high stability.

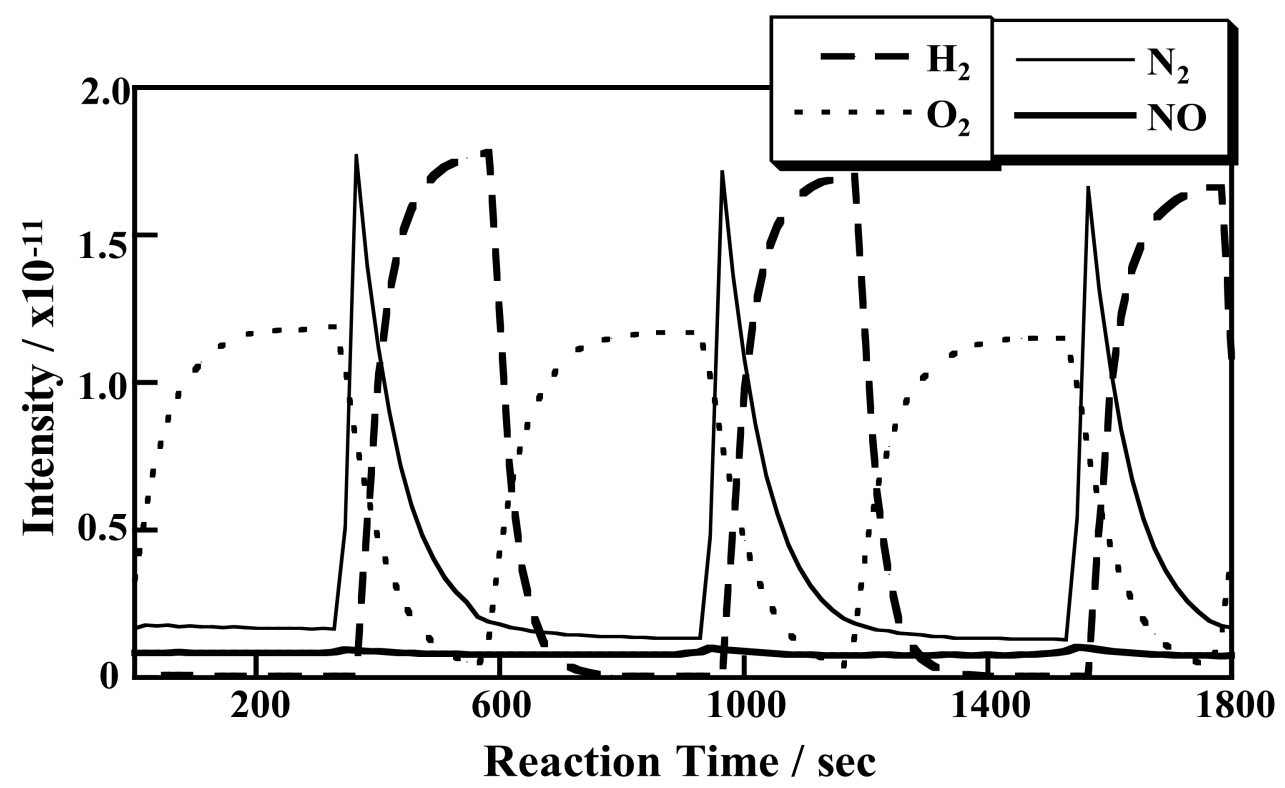

Figure 4. NOx storage-reduction cycle.

As shown in Figure 5, when a mixed gas of $\mathrm{NO}$ and $\mathrm{O}_{2}$ was introduced to the reduced sample at $573 \mathrm{~K}$, a strong IR band of adsorbed $\mathrm{NO}_{3}{ }^{-}$species was observed at $1369 \mathrm{~cm}^{-1}$, which disappeared quickly just after replacing the gas phase with $\mathrm{H}_{2}$, showing the fast response of NSR processes. 

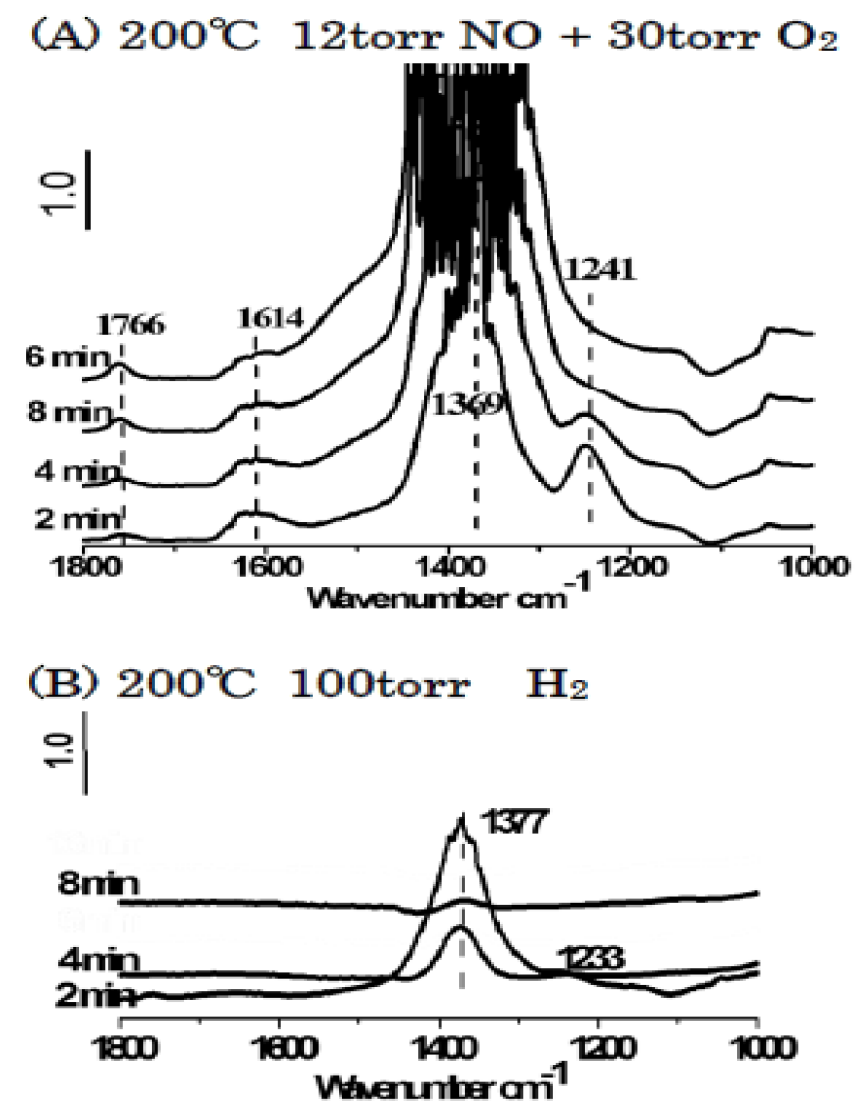

Figure 5. FT-IR spectra of redox process; (A) storage (B) reduction.

In situ XPS measurements were carried out to identify $\mathrm{NO}_{\mathrm{x}}$-storage and $\mathrm{H}_{2}$-reduced states more clearly. After $\mathrm{NO}_{x}$ storage, the existence of surface $\mathrm{KNO}_{3}$ species was confirmed by strong K 2p (292.9 and $295.5 \mathrm{eV}), \mathrm{N} 1 \mathrm{~s}(407.1 \mathrm{eV})$, and $\mathrm{O} 1 \mathrm{~s}(532.7 \mathrm{eV})$ transition peaks. However, the XPS peaks of Ti $2 \mathrm{p}$ and $\mathrm{Pt} 4 \mathrm{f}$ transitions were scarcely observed, indicating that the KTN support surface was mostly covered with $\mathrm{KNO}_{3}$ overlayers. After in situ reduction by $\mathrm{H}_{2}$, the $\mathrm{N}$ 1s peak disappeared; instead, the intensities of Ti 2p (457.8 and $463.5 \mathrm{eV})$ and Pt $4 \mathrm{f}(69.5$ and $73.0 \mathrm{eV})$ peaks were increased significantly, indicating the complete removal of $\mathrm{KNO}_{3}$ from the surface of $\mathrm{KTN}$ support. At the same time, the binding energy of the K 2p peak shifted to the same position as KTN support (292.0 and $294.8 \mathrm{eV})$, although the intensity ratio of $(\mathrm{K} 2 \mathrm{p})$ / ( Ti 2p) was greater than that of KTN itself. These results clearly indicate that in the reduction process, potassium cations may be transferred into KTN bulk, forming K-rich surface layers of KTN.

Figure 6 summarizes a mechanism of the preparation of active phase and $\mathrm{NO}_{\mathrm{x}}$ storage/reduction over $\mathrm{Pt} / \mathrm{KNO}_{3} / \mathrm{KTN}$ catalysts. During the storage process, $\mathrm{NO}$ is oxidized on $\mathrm{Pt}$, forming $\mathrm{NO}_{2}$, which reacts with $\mathrm{K}$ cations of the K-rich surface layer to form $\mathrm{KNO}_{3}$. Formed $\mathrm{NO}_{x}$ storage species may easily move over the surface and finally cover the entire surface of $\mathrm{KTN}$, achieving high $\mathrm{NO}_{x}$ storage capacity. During the $\mathrm{NO}_{\mathrm{x}}$ reduction process, the formed $\mathrm{KNO}_{3}$ is reduced to $\mathrm{N}_{2}$ and $\mathrm{H}_{2} \mathrm{O}$, and $\mathrm{K}$ cations move back to $\mathrm{KTN}$, forming K-rich surface layers of KTN again. 


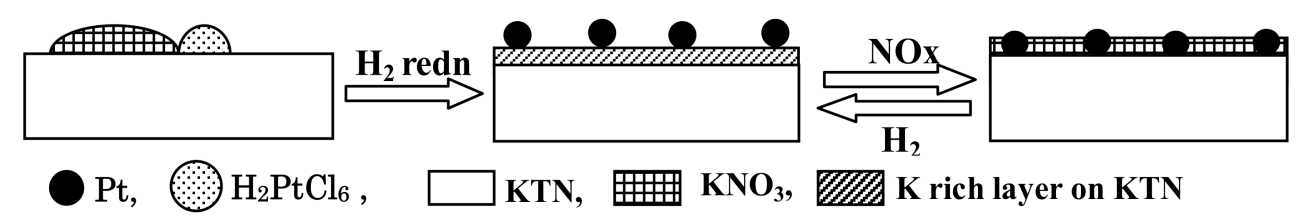

Figure 6. Possible scheme of preparation, storage-reduction cycles of $\mathrm{Pt} / \mathrm{KNO}_{3} / \mathrm{KTN}$.

2.1.2. Activity and Selectivity-Controlling Factors for $\mathrm{NO}_{x}$ Storage-Reduction Process by Pt-Alkali Metal Nanocomposites Supported on $\mathrm{TiO}_{2}$ with Different Crystal Structures

As described in the previous section, we have found that K-titanate nanobelt- (KTN: $\mathrm{K}_{2} \mathrm{Ti}_{8} \mathrm{O}_{17}$ ) supported $\mathrm{Pt} / \mathrm{KNO}_{3} \mathrm{NSR}$ catalysts exhibited a high $\mathrm{NO}_{\mathrm{x}}$ storage capacity and excellent redox behavior. In this section, we employed different crystal-structured $\mathrm{TiO}_{2}$ with various loading amounts of $\mathrm{Pt}(0.5-5 \mathrm{wt} \%)$ and $\mathrm{MeNO}_{3}(\mathrm{Me}=\mathrm{Na}, \mathrm{K}, \mathrm{Rb} ; 1.0-40 \mathrm{wt} \%)$ to elucidate the activity and selectivity-controlling factors for NSR processes.

The K-titanate nanobelt $\left(\mathrm{K}_{2} \mathrm{Ti}_{8} \mathrm{O}_{17}: \mathrm{KTN}\right)$ was prepared by hydrothermal treatment using $\mathrm{TiO}_{2}(\mathrm{P}-25)$ and $\mathrm{KOH}$. Various amounts of $\mathrm{Pt}$ and $\mathrm{KNO}_{3}$ were loaded on $\mathrm{KTN}$ $\left(350 \mathrm{~m}^{3}\right)$, ST-01(Anatase; $\left.\left.270 \mathrm{~m}^{2}\right)\right)$, MT150 A (Rutile; $\left.100 \mathrm{~m}^{2}\right)$, and P-25(A/R = 0.8; $\left.50 \mathrm{~m}^{2}\right)$ supports by a conventional impregnation method. After reduction of the catalyst $(0.1 \mathrm{~g})$ at $623 \mathrm{~K}$, a $\mathrm{NO}_{\mathrm{x}}$ storage process (lean; $80 \mathrm{~mL} / \mathrm{min}$ of $930 \mathrm{ppm} \mathrm{NO} / 7 \% \mathrm{O}_{2} / \mathrm{He}$ at $623 \mathrm{~K}$ ) was performed on a gas-flow system, and the output gas was analyzed by mass spectroscopy, followed by a rich process of $80 \mathrm{~mL} / \mathrm{min}$ of $4 \% \mathrm{H}_{2} / \mathrm{He}$ flow. The lean-rich cycle experiments were carried out using an interval of 6 min of $\mathrm{NO}_{\mathrm{x}}(930 \mathrm{ppm})$ and $4 \mathrm{~min}$ of $\mathrm{H}_{2}(4 \%)$ with $80 \mathrm{~mL} / \mathrm{min}$ flow.

Table 1 summarizes $\mathrm{NO}_{\mathrm{x}}$ storage and reduction properties of $1.5 \mathrm{wt} \% \mathrm{Pt}$-Alkali metal (Pt:Me $=1: 31 \& 1: 61$ ) catalysts supported on various carriers. The results indicated that full NO trapping periods and NO stored amounts were strongly dependent on surface area, pore volume, and Pt particle size. The KTN- and ST-01- (anatase) supported catalysts showed more efficient catalytic behavior than the others.

Table 1. Full trapping period, NO stored amount and $\mathrm{N}_{2}$ desorbed.

\begin{tabular}{|c|c|c|c|c|c|c|}
\hline Catalysts & $\begin{array}{l}\text { Surf. Area. } \\
\text { (Pore vol.) }\end{array}$ & $\begin{array}{c}\mathrm{MeNO}_{3} \\
\text { Loaded } \\
(w \mathrm{t} \%)\end{array}$ & $\begin{array}{c}\text { Pt Size TEM } \\
(\mathrm{nm})\end{array}$ & $\begin{array}{l}\text { Full Trapping } \\
\text { Period (min) }\end{array}$ & $\begin{array}{l}\text { NO Stored } \\
(\mathrm{mmol} / \mathrm{g})\end{array}$ & $\begin{array}{c}\mathrm{N}_{2} \text { Desorb. } \\
(\mathrm{mmol} / \mathrm{g})\end{array}$ \\
\hline \multirow{2}{*}{$\begin{array}{l}\mathrm{TiO}_{2}(\mathrm{~A}) \\
{[\mathrm{ST}-01]}\end{array}$} & \multirow{2}{*}{$\begin{array}{c}275 \mathrm{~m}^{2} / \mathrm{g} \\
\left(0.63 \mathrm{~cm}^{3} / \mathrm{g}\right)\end{array}$} & K (20) & \multirow{2}{*}{$2-3$} & 2 & 0.92 & 0.45 \\
\hline & & K (33) & & 18 & 2.45 & 1.11 \\
\hline \multirow{2}{*}{$\begin{array}{c}\mathrm{TiO}_{2}(\mathrm{R}) \\
{[\mathrm{MT150} \text { A] }}\end{array}$} & \multirow{2}{*}{$\begin{array}{c}101 \mathrm{~m}^{2} / \mathrm{g} \\
\left(0.36 \mathrm{~cm}^{3} / \mathrm{g}\right)\end{array}$} & K (20) & \multirow{2}{*}{$3-4$} & 5 & 0.77 & 0.40 \\
\hline & & K (33) & & 1 & 1.71 & 0.66 \\
\hline \multirow{2}{*}{$\begin{array}{c}\mathrm{TiO}_{2}(\mathrm{~A} / \mathrm{R}) \\
{[\mathrm{P}-25]}\end{array}$} & \multirow{2}{*}{$\begin{array}{c}54 \mathrm{~m}^{2} / \mathrm{g} \\
\left(0.10 \mathrm{~cm}^{3} / \mathrm{g}\right)\end{array}$} & K (20) & \multirow{2}{*}{$3-4$} & 13 & 1.53 & 0.56 \\
\hline & & K (33) & & 8 & 1.28 & 0.67 \\
\hline \multirow{4}{*}{$\begin{array}{c}\mathrm{K}_{2} \mathrm{Ti}_{8} \mathrm{O}_{17} \\
{[\mathrm{KTN}]}\end{array}$} & \multirow{4}{*}{$\begin{array}{c}320 \mathrm{~m}^{2} / \mathrm{g} \\
\left(0.01 \mathrm{~cm}^{3} / \mathrm{g}\right)\end{array}$} & K (20) & \multirow{2}{*}{$1-2$} & 25 & 1.57 & 0.67 \\
\hline & & K (33) & & 34 & 2.53 & 1.10 \\
\hline & & $\mathrm{Na}(28)$ & $2-3$ & 23 & 1.50 & 0.71 \\
\hline & & $\mathrm{Rb}(27)$ & $3-4$ & 16 & 1.28 & 0.59 \\
\hline
\end{tabular}

Figure 7 shows the lean-rich cycle experiments over $1.5 \mathrm{wt} \% \mathrm{Pt}-33 \mathrm{wt} \% \mathrm{KNO}_{3} / \mathrm{KTN}_{\text {, }}$

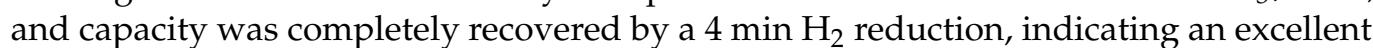
$\mathrm{NO}_{x}$ trapping capacity with high stability. However, in the latter case, a considerable amount of NO was detected at the later stage of the lean cycle, indicating an important role for the ordered-layer structure of K cations. Table 2 summarizes the in situ XPS results of the $\mathrm{NO}_{\mathrm{x}}$-storage and $\mathrm{H}_{2}$-reduced states. In the case of $\mathrm{KTN}$-supported catalyst, only $\mathrm{N} 1 \mathrm{~s}$, $\mathrm{O} 1 \mathrm{~s}$, and $\mathrm{K} 2 \mathrm{p}$ transitions assignable to $\mathrm{KNO}_{3}$ were observed in the NSR state, without 
any peaks assignable to KTN. Accordingly, $\mathrm{NO}$ is oxidized into $\mathrm{NO}_{2}$ and combined with the K-rich layer to form $\mathrm{KNO}_{3}$, which covers the entire surface of KTN support.

(a)

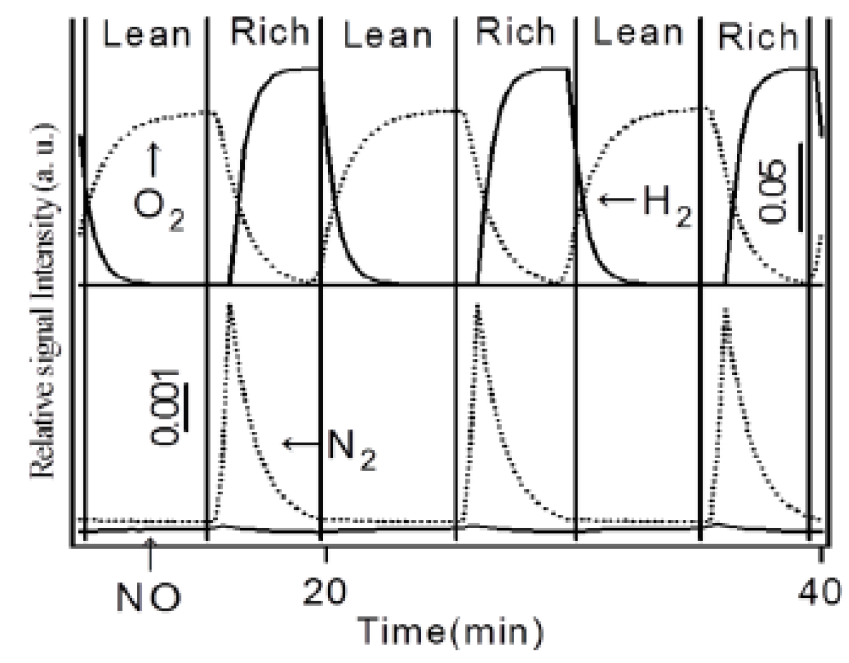

(b)

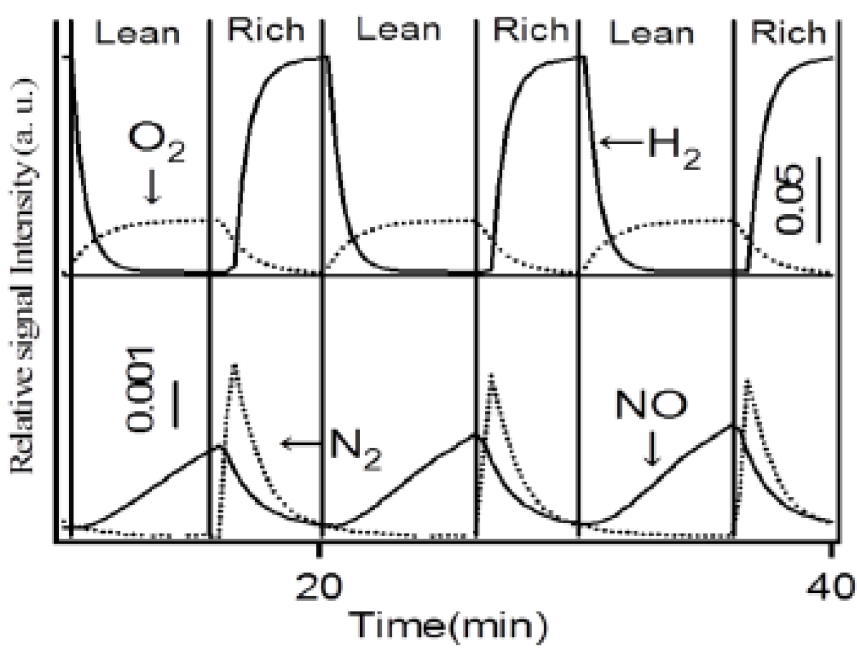

Figure 7. $\mathrm{NO}_{\mathrm{x}}$ storage-reduction cycles at $623 \mathrm{~K}$. (a) $1.5 \mathrm{wt} \% \mathrm{Pt}-33 \mathrm{wt} \% \mathrm{KNO}_{3} / \mathrm{KTN}$, (b) $1.5 \mathrm{wt} \% \mathrm{Pt}-33 \mathrm{wt} \% \mathrm{KNO}_{3} / \mathrm{TiO} 2(\mathrm{ST}-01)$.

Table 2. Binding-energy $(\mathrm{eV})$ changes during $\mathrm{NO}_{\mathrm{x}}$ stored and reduction processes of $1.5 \mathrm{wt} \% \mathrm{Pt}-33 \mathrm{wt} \% \mathrm{KNO}_{3} / \mathrm{KTN}$ and $1.5 \mathrm{wt} \% \mathrm{Pt}-33 \mathrm{wt} \% \mathrm{KNO}_{3} / \mathrm{TiO}_{2}(\mathrm{ST}-01)$ by in situ XPS.

\begin{tabular}{|c|c|c|c|c|c|c|}
\hline Catalysts & Condition & $\operatorname{Pt} 4 f_{7 / 2}$ & $\operatorname{Ti} 2 \mathrm{p}_{3 / 2}$ & $\mathrm{~K} 2 \mathrm{p}_{3 / 2}$ & N 1s & O 1s \\
\hline \multirow{2}{*}{$\mathrm{Pt}-\mathrm{KNO}_{3} / \mathrm{KTN}$} & $\mathrm{NO}_{\mathrm{x}}$ stored & $-(0)$ & $457.7(0.01)$ & $292.7(2.3)$ & 407.1 & $532.8(1)$ \\
\hline & $\mathrm{H}_{2}$ reduced & $69.2(1)$ & $457.7(1)$ & $292.2(1)$ & - & $529.4(1)$ \\
\hline \multirow{3}{*}{$\mathrm{Pt}-\mathrm{KNO}_{3} / \mathrm{TiO}_{2}(\mathrm{ST}-01)$} & & $73.7(0.8)$ & $457.8(1.1)$ & $292.4(0.9)$ & 406.9 & $529.2(0.8)$ \\
\hline & $\mathrm{NU}_{\mathrm{x}}$ stored & $70.5(0.2)$ & $45 / .8(1.1)$ & $292.4(0.9)$ & 406.9 & $532.1(0.2)$ \\
\hline & $\mathrm{H}_{2}$ reduced & $70.5(1)$ & $458.0(1)$ & $292.7(1)$ & - & $530.0(1)$ \\
\hline
\end{tabular}

In the reduced state, all the transitions assigned to $\mathrm{KNO}_{3}$ disappeared completely, indicating a reduction of $\mathrm{KNO}_{3}$, and $\mathrm{K}^{+}$moved back to KTN, forming a K-rich layer. On the other hand, in the case of $\mathrm{TiO}_{2}$ (ST-01) supported catalysts, the Ti $2 p$ and $\mathrm{K} 2 \mathrm{p}$ peaks did not change much during $\mathrm{NO}_{x}$ redox cycles, indicating poor dispersion of $\mathrm{K}$ cations on the surface, which would be the reason for their lower $\mathrm{NO}_{\mathrm{x}}$ storage capacity and slower response. Table 2 summarizes the in situ XPS results of the $\mathrm{NO}_{x}$-storage and $\mathrm{H}_{2}-$ reduced states. In the case of KTN-supported catalysts, only N 1s, O 1s, and $2 p$ transitions assignable to $\mathrm{KNO}_{3}$ were observed in the NSR state, without any peaks assignable to KTN. Accordingly, $\mathrm{NO}$ was oxidized into $\mathrm{NO}_{2}$ and combined with the K-rich layer to form $\mathrm{KNO}_{3}$, which covered the entire surface of the KTN support. In the reduced state, all the transitions assigned to $\mathrm{KNO}_{3}$ disappeared completely, indicating the reduction of $\mathrm{KNO}_{3}$, and $\mathrm{K}^{+}$moved back to KTN, forming a K-rich layer. On the other hand, in the case of $\mathrm{TiO}_{2}$ - (ST-01) supported catalysts, the Ti $2 \mathrm{p}$ and $\mathrm{K} 2 \mathrm{p}$ peaks did not change much during $\mathrm{NO}_{x}$ redox cycles, indicating poor dispersion of $\mathrm{K}$ cations on the surface, which would be the reason for their lower $\mathrm{NO}_{x}$ storage capacity and slower response. The following three factors may be important for efficient NSR catalysts in Pt-alkali metal/ $/ \mathrm{TiO}_{2}$ systems: (1) smaller Pt particles for $\mathrm{NO}$ oxidation and $\mathrm{KNO}_{3}$ reduction, (2) facile migration of alkali cations from and back to subsurface layers during redox cycles, and (3) the existence of a certain surface structure to maintain high dispersion of alkali cations. 
2.1.3. Mechanistic Study of $\mathrm{NO}_{\mathrm{x}}$ Storage and Reduction Behavior by In Situ XPS and FTIR over $\mathrm{Pt} / \mathrm{K} / \mathrm{CeO}_{2}$ and $\mathrm{Pt} / \mathrm{K} / \mathrm{ZrO}_{2}$ NSR Catalysts

Since the pioneering work of $\mathrm{NO}_{x}$ storage-reduction (NSR) catalysts by Toyota's research group, many studies have been reported on the mechanism of NSR reaction over $\mathrm{Pt}-\mathrm{BaO} / \mathrm{Al}_{2} \mathrm{O}_{3}$ catalysts. The generally accepted mechanism for this reaction is " $\mathrm{NO}_{2}$ transfer from $\mathrm{Pt}$ to $\mathrm{BaO}^{\prime \prime}$ forming $\mathrm{Ba}\left(\mathrm{NO}_{3}\right)_{2}$ surface layers. As previously mentioned, we have proposed a novel " $\mathrm{K}^{+}$transfer mechanism from and back to K-rich titanate surface layers" for Pt/ $\mathrm{KNO}_{3} / \mathrm{K}$-titanate NSR catalysts [33]. In the present study, we investigated the mechanism of NSR processes over $\mathrm{Pt} / \mathrm{KNO}_{3} / \mathrm{CeO}_{2}$ and $\mathrm{Pt} / \mathrm{KNO}_{3} / \mathrm{ZrO}_{2}$ by means of in situ XPS and FT-IR during the reaction. We found that under lean conditions, $\mathrm{KNO}_{3}$-like species are stored below the $\mathrm{PtCeO}_{3}\left(\mathrm{PtO} \cdot \mathrm{CeO}_{2}\right)$ top layers, and under rich conditions, $\mathrm{K}^{+}$ may be stabilized in the $\mathrm{K}_{2} \mathrm{Ce}_{2} \mathrm{O}_{4}\left(\mathrm{~K}_{2} \mathrm{O} \cdot \mathrm{Ce}_{2} \mathrm{O}_{3}\right)$ top layers in a way similar to the " $\mathrm{K}^{+}$ transfer mechanism".

Figure 8 shows the time courses of outlet NO during the NOx storage process at $350{ }^{\circ} \mathrm{C}$. Over ceria-supported catalysts, the full trapping period and the amounts of stored $\mathrm{NOx}$ increased with the increase in added $\mathrm{KNO}_{3}$. Figure 9 shows the lean-rich cycle experiments over $\mathrm{Pt} / 2.5 \mathrm{~K} / \mathrm{CeO}_{2}$ and $\mathrm{Pt} / 3.5 \mathrm{~K} / \mathrm{CeO}_{2}$ catalysts. In the case of $3.5 \mathrm{mmol}$ of $\mathrm{KNO}_{3}$-added catalyst, almost all of the $\mathrm{NO}_{x}$ was stored for $6 \mathrm{~min}$, and the capacity was completely recovered by a $4 \mathrm{~min} \mathrm{H}_{2}$ reduction, indicating an excellent $\mathrm{NO}_{\mathrm{x}}$ trapping capacity with high stability. However, over $2.5 \mathrm{mmol}$ of $\mathrm{KNO}_{3}$-added catalyst, a small amount of $\mathrm{NO}$ was detected at the later stage of the lean cycle.

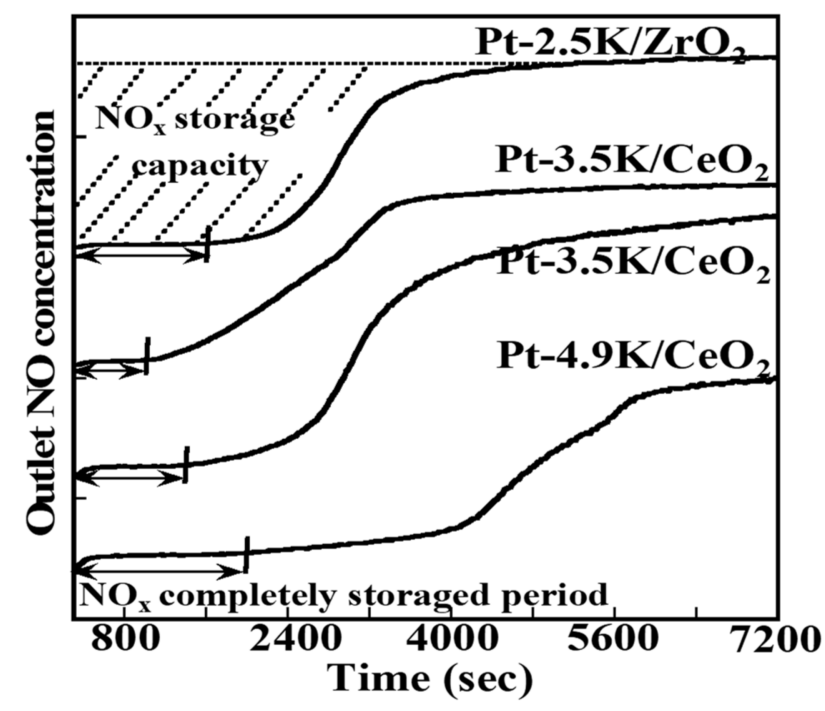

Figure 8. Time courses of outlet NO during NSR process at $350{ }^{\circ} \mathrm{C}$.

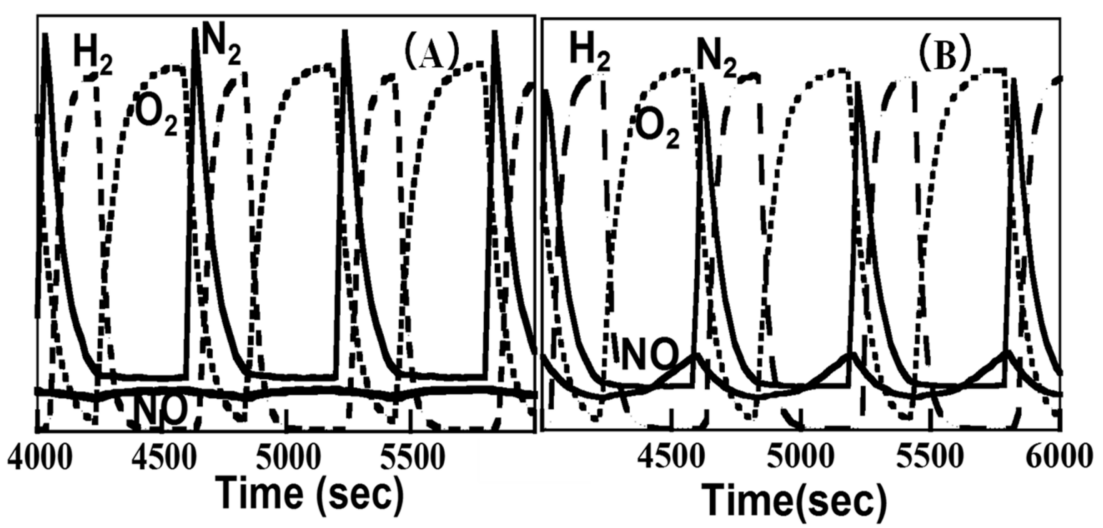

Figure 9. Lean-rich cycles at $350{ }^{\circ} \mathrm{C}$. (A) $\mathrm{Pt} / 2.5 \mathrm{~K} / \mathrm{CeO}_{2}$, (B) $\mathrm{Pt} / 3.5 \mathrm{~K} / \mathrm{CeO}_{2}$. 
Table 3 summarizes the full NO trapping periods during a lean process, total amounts of stored $\mathrm{NO}_{\mathrm{x}}$, and desorbed $\mathrm{N}_{2}$ over various catalysts. Both $\mathrm{ZrO}_{2}$ and $\mathrm{CeO}_{2}$-supported catalysts exhibited excellent NRS behavior at $350{ }^{\circ} \mathrm{C}$. In the case of $\mathrm{CeO}_{2}$-supported catalysts, the full trapping period and the amount of stored $\mathrm{NO}_{\mathrm{x}}$ increased with the increase in added $\mathrm{KNO}_{3}$, and the highest storage capacity of $2.4 \mathrm{mmol} / \mathrm{g}$ with the longest trapping period, of $29 \mathrm{~min}$, was achieved in the case of $4.9 \mathrm{mmol}$ of $\mathrm{KNO}_{3}$-added catalyst. The particle size of $\mathrm{Pt}$ was very small and could not be detected by TEM after $\mathrm{H}_{2}$ reduction. On the contrary, over $\mathrm{ZrO}_{2}$-supported catalysts, a decrease in the trapping periods and nearly constant $\mathrm{NO}_{x}$ storage amounts were observed with the increase in added $\mathrm{KNO}_{3}$.

Table 3. Full trapping period (min), Amount of stored $\mathrm{NO}$ and Desorbed $\mathrm{N}_{2}$ (mmol/g-cat).

\begin{tabular}{cccc}
\hline Catalysts & Trapping Period & $\mathbf{N O}_{\mathbf{x}}$ Stored & $\mathbf{N}_{\mathbf{2}}$ Desorbed \\
\hline $\mathrm{Pt} / 2.5 \mathrm{~K} / \mathrm{ZrO}_{2}$ & 20.7 & 1.2 & 0.7 \\
$\mathrm{Pt} / 3.5 \mathrm{~K} / \mathrm{ZrO}_{2}$ & 18.3 & 1.3 & 0.8 \\
$\mathrm{Pt} / 4.9 \mathrm{~K} / \mathrm{ZrO}_{2}$ & 15.8 & 1.5 & 0.9 \\
$\mathrm{Pt} / 2.5 \mathrm{~K} / \mathrm{CeO}_{2}$ & 18.6 & 1.1 & 0.7 \\
$\mathrm{Pt} / 3.5 \mathrm{~K} / \mathrm{CeO}_{2}$ & 24.1 & 1.6 & 0.9 \\
$\mathrm{Pt} / 4.9 \mathrm{~K} / \mathrm{CeO}_{2}$ & 28.6 & 2.4 & 1.5 \\
\hline
\end{tabular}

In situ XPS measurements were carried out to identify $\mathrm{NO}_{\mathrm{x}}$-stored and $\mathrm{H}_{2}$-reduced states (Figure 10 and Table 4). After $\mathrm{NO}_{x}$ storage, the existence of $\mathrm{KNO}_{3}$ species was confirmed by K 2p(292.7 eV), N 1s $(407.1 \mathrm{eV})$ and O 1s (532.6 eV) transition peaks, although their intensities were not as strong as those of $\mathrm{Pt} 4 \mathrm{f}\left(72.3 \mathrm{eV} ; \mathrm{Pt}^{2+}\right)$ and $\mathrm{Ce} 3 \mathrm{~d}\left(889.0 \mathrm{eV} ; \mathrm{Ce}^{4+}\right)$ peaks. These results suggest that $\mathrm{KNO}_{3}$-like species are stored below the $\mathrm{PtCeO}\left(\mathrm{PtO} \cdot \mathrm{CeO}_{2}\right)$ top layers. After in situ reduction by $\mathrm{H}_{2}$, the $\mathrm{N}$ 1s peak disappeared with the large increase in $\mathrm{K} 2 \mathrm{p}(293.6 \mathrm{eV})$ and the shift of $\mathrm{Ce} 3 \mathrm{~d}\left(88.5 \mathrm{eV} ; \mathrm{Ce}^{3+}\right)$ peaks. At the same time, the Pt4 $\mathrm{f}\left(70.6 \mathrm{eV} ; \mathrm{Pt}^{0}\right)$ peak decreased significantly, indicating the complete removal of $\mathrm{KNO}_{3}$, together with the reduction of $\mathrm{Pt}$. Accordingly, under rich conditions, $\mathrm{K}^{+}$may be stabilized as $\mathrm{K}_{2} \mathrm{Ce}_{2} \mathrm{O}_{4}\left(\mathrm{~K}_{2} \mathrm{O} \cdot \mathrm{Ce}_{2} \mathrm{O}_{3}\right)$ on the top layers of ceria support and phase transfer between $\mathrm{PtCeO}_{3}$ (lean), and $\mathrm{K}_{2} \mathrm{Ce}_{2} \mathrm{O}_{4}$ (rich) surface nanocomposites is responsible for high capacity and durability, which is realized by facile combination of $\mathrm{Ce}^{3+} \Leftrightarrow \mathrm{Ce}^{4+}$ and $\mathrm{Pt}^{0} \Leftrightarrow \mathrm{Pt}^{2+}$ redox cycles. On the contrary, over $\mathrm{Pt}-\mathrm{K} / \mathrm{ZrO}_{2}$, because of the absence of a $\mathrm{Zr}^{3+} \Leftrightarrow \mathrm{Zr}^{4+}$ redox cycle, sintering of $\mathrm{PtO}_{2}$ (lean) and $\mathrm{K}_{2} \mathrm{O}$ (rich) easily takes place during lean-rich cycles, which causes the deactivation.
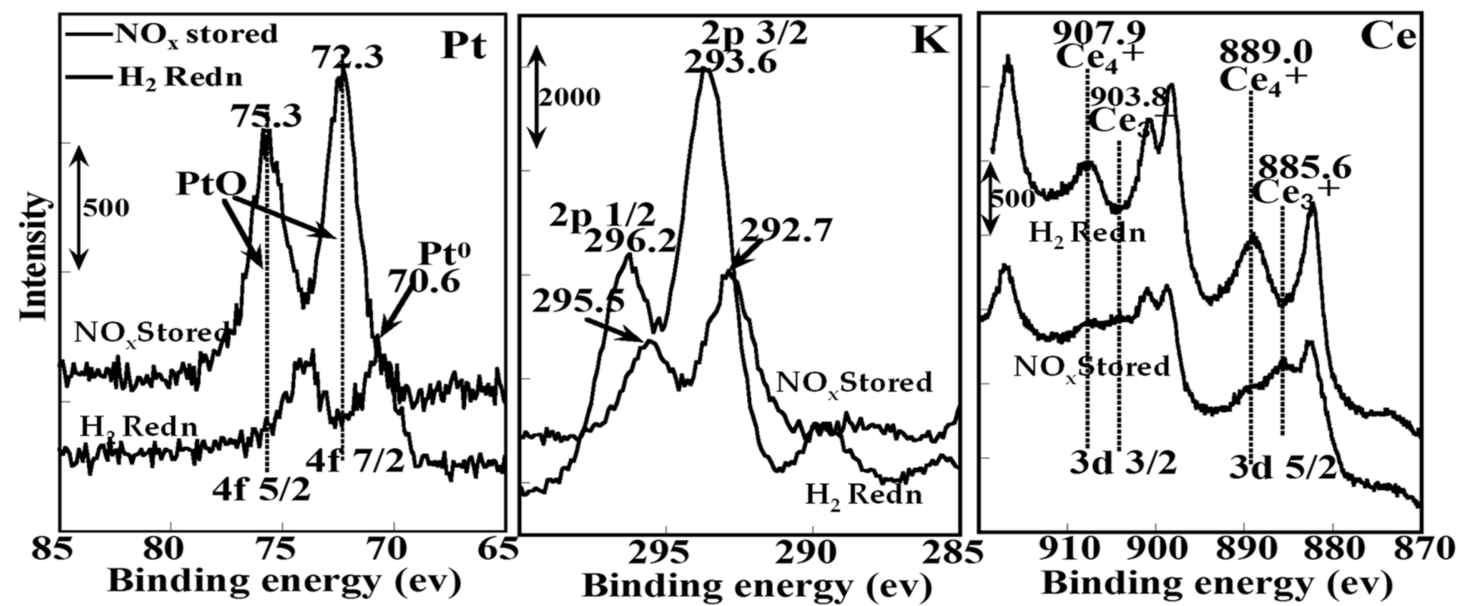

Figure 10. XPS spectra of Pt-3.5 K/CeO 2 catalyst. 
Table 4. B.E. $(\mathrm{eV})$ changes during $\mathrm{NO}_{\mathrm{x}}$ NSR processes of Pt-3.5 $\mathrm{K} / \mathrm{CeO}_{2}$ by in situ XPS. (Numbers in parentheses show relative intensity ratio of oxidized and reduced catalysts.).

\begin{tabular}{cccccc}
\hline & $\mathbf{P t} \mathbf{4} \mathbf{f}_{\mathbf{7 / 2}}$ & $\mathbf{K} \mathbf{2} \mathbf{p}_{\mathbf{3} / \mathbf{2}}$ & $\mathbf{C e} \mathbf{3} \mathbf{d}_{\mathbf{5 / 2}}$ & $\mathbf{N} \mathbf{1 s}$ & $\mathbf{O} \mathbf{~ s}$ \\
\hline Reference & 71.0 & 292.7 & 883.1 & 398.1 & 533.2 \\
$\mathrm{NO}_{\mathbf{x}}$ stored & $72.3(5)$ & $292.7(0.3)$ & $889.0(1.2)$ & 407.1 & $532.6,529.0$ \\
$\mathrm{H}_{2}$ reduced & $70.6(1)$ & $293.6(1)$ & $885.6(1)$ & - & $531.6,529.0$ \\
\hline
\end{tabular}

2.1.4. Comparison of $\mathrm{NO}_{x}$ Storage and Reduction Behaviors among Ceria-Supported $\mathrm{Pt}-\mathrm{KNO}_{3}, \mathrm{Cu}-\mathrm{KNO}_{3}$, and $\mathrm{Co}-\mathrm{KNO}_{3}$ NSR Catalysts

As mentioned in the previous section, we have reported that $\mathrm{Pt}$ and a $\mathrm{KNO}_{3}$-loaded K-titanate nanobelt $\left(\mathrm{K}_{2} \mathrm{Ti}_{8} \mathrm{O}_{17}\right)$ exhibited the highest $\mathrm{NO}_{x}$ storage capacity $(2.3 \mathrm{mmol} / \mathrm{g})$, at $350{ }^{\circ} \mathrm{C}$, among the relevant literature and proposed a novel $\mathrm{K}$ cation transfer mechanism from and back to $\mathrm{K}$-rich titanate surface layers during storage-reduction cycles [33]. We extended our study to a $\mathrm{KNO}_{3}$-added $\mathrm{Pt} / \mathrm{CeO}_{2}$ system, which also exhibited high $\mathrm{NO}_{\mathrm{x}}$ storage capacity and good redox cycle behavior as NSR catalysts. Moreover, we substituted $\mathrm{Pt}$ with $\mathrm{Cu}$ or $\mathrm{Co}$ and compared their catalytic behaviors by applying a kinetic investigation, as well as in situ XPS and FT-IR measurements during the reaction. It is revealed that under lean conditions, $\mathrm{KNO}_{3}$-like species are stored underneath the $\mathrm{MeCeO}_{3}\left(\mathrm{MeO} \cdot \mathrm{CeO}_{2}\right.$; $\mathrm{Me}=\mathrm{Pt}, \mathrm{Cu}$ or $\mathrm{Co}$ ) top layers, and under rich conditions, $\mathrm{K}^{+}$may emerge to the surface and stabilize in the $\mathrm{K}_{2} \mathrm{Ce}_{2} \mathrm{O}_{4}\left(\mathrm{~K}_{2} \mathrm{O} \cdot \mathrm{Ce}_{2} \mathrm{O}_{3}\right)$ top layers in a way similar to the " $\mathrm{K}^{+}$transfer mechanism of $\mathrm{Pt} / \mathrm{KNO}_{3} / \mathrm{K}$-titanate nanobelt".

Various catalysts were prepared by a conventional impregnation method. After reduction of catalysts $(0.2 \mathrm{~g})$ at $350{ }^{\circ} \mathrm{C}$, a $\mathrm{NO}_{\mathrm{x}}$ storage process (lean; $80 \mathrm{~mL} / \mathrm{min}$ of $930 \mathrm{ppm}$ $\mathrm{NO} / 7 \% \mathrm{O}_{2} / \mathrm{He}$ ) was performed on a gas-flow system, and the output gas was analyzed by mass spectroscopy, followed by a rich process of $80 \mathrm{~mL} / \mathrm{min}$ of $4 \% \mathrm{H}_{2} / \mathrm{He}$ flow. The lean-rich cycle experiments were carried out.

Table 5 summarizes the full NO trapping periods during a lean process, total amounts of stored $\mathrm{NO}_{\mathrm{x}}$, and desorbed $\mathrm{N}_{2}$ over various catalysts at $350{ }^{\circ} \mathrm{C}$. In the case of $\mathrm{Pt}(0.08 \mathrm{mmol} / \mathrm{g}$-cat. $)-\mathrm{x} \mathrm{KNO}_{3} / \mathrm{CeO}_{2}$ catalysts, the full trapping period and the amount of stored $\mathrm{NO}_{\mathrm{x}}$ increased with the increase in added $\mathrm{KNO}_{3}$ (x mmol/g-cat.), and the highest storage capacity of $2.4 \mathrm{mmol} / \mathrm{g}$ with the longest trapping period of $29 \mathrm{~min}$ was achieved in the case of $4.9 \mathrm{mmol}$ of $\mathrm{KNO}_{3}$-added catalyst. It is worth noticing that $\mathrm{Cu}$ - and Co-loaded catalysts showed better NSR behaviors than the Pt-loaded catalyst, probably because of the participation of $\mathrm{Cu}$ or $\mathrm{Co}$ cations as $\mathrm{NO}_{\mathrm{x}}$ storage species. The Pt particles were very small and could not be detected by XRD or TEM, whereas weak XRD peaks of $\mathrm{Cu}$ or Co metals were detected after $\mathrm{H}_{2}$ reduction.

Table 5. Full trapping periods, amounts of stored NO, and desorbed N2 (mmol/g-cat.) at $350{ }^{\circ} \mathrm{C}$.

\begin{tabular}{cccc}
\hline Catalysts & Trapping Period & $\mathbf{N O}_{\mathbf{x}}$ Stored & $\mathbf{N}_{\mathbf{2}}$ Desorbed \\
\hline $\mathrm{Pt}-2.5 \mathrm{~K} / \mathrm{CeO}_{2}$ & $19 \mathrm{~min}$ & 1.1 & 0.6 \\
$\mathrm{Pt}-3.3 \mathrm{~K} / \mathrm{CeO}_{2}$ & $24 \mathrm{~min}$ & 1.6 & 0.9 \\
$\mathrm{Pt}-4.9 \mathrm{~K} / \mathrm{CeO}_{2}$ & $29 \mathrm{~min}$ & 2.4 & 1.1 \\
$\mathrm{Cu} / 1.3 \mathrm{~K} / \mathrm{CeO}_{2}$ & $16 \mathrm{~min}$ & 1.9 & 0.8 \\
$\mathrm{Co} / 1.3 \mathrm{~K} / \mathrm{CeO}_{2}$ & $15 \mathrm{~min}$ & 1.1 & 0.5 \\
\hline
\end{tabular}

Figure 11 shows the lean-rich cycle experiments at $350{ }^{\circ} \mathrm{C}$ over $\mathrm{Pt}(0.08 \mathrm{mmol})-\mathrm{KNO}_{3}$ $(3.5 \mathrm{mmol}) / \mathrm{CeO}_{2}$ and $\mathrm{Cu}$ or $\mathrm{Co}(0.88 \mathrm{mmol})-\mathrm{KNO}_{3}(1.3 \mathrm{mmol}) / \mathrm{CeO}_{2}$ catalysts. In the cases of $\mathrm{Pt}$ and $\mathrm{Cu}$ catalysts, complete $\mathrm{NO}_{x}$ removal and recovery by $\mathrm{H}_{2}$ reduction were observed, whereas a small amount of $\mathrm{NO}$ was detected at the later stage of the lean cycle in the case of Co catalysts. In situ XPS measurements were carried out to identify $\mathrm{NO}_{x}$-stored and $\mathrm{H}_{2}$-reduced states (Table 6). After $\mathrm{NO}_{\mathrm{x}}$ storage, the existence of $\mathrm{KNO}_{3}$ species was confirmed by K $2 \mathrm{p}(292.7 \mathrm{eV}), \mathrm{N} 1 \mathrm{~s}(407.1 \mathrm{eV})$, and $\mathrm{O} 1 \mathrm{~s}(532.6 \mathrm{eV})$ transition peaks, although their intensities were not as strong as those of $\mathrm{Pt} 4 \mathrm{f}\left(72.3 \mathrm{eV} ; \mathrm{Pt}^{2+}\right), \mathrm{Cu} 2 \mathrm{p}\left(933.7 \mathrm{eV} ; \mathrm{Cu}^{2+}\right)$ 
and $\mathrm{Ce} 3 \mathrm{~d}\left(889.0 \mathrm{eV} ; \mathrm{Ce}^{4+}\right)$ peaks. These results suggest that $\mathrm{KNO}_{3}$-like species are stored in the buried form below the top layers. After in situ reduction by $\mathrm{H}_{2}$, the $\mathrm{N} 1 \mathrm{~s}$ peak disappeared with the large increase in $\mathrm{K} 2 \mathrm{p}(293.6 \mathrm{eV})$ and the shift of $\mathrm{Ce} 3 \mathrm{~d}\left(88.5 \mathrm{eV} ; \mathrm{Ce}^{3+}\right)$ peaks. Accordingly, under rich conditions, $\mathrm{K}^{+}$may be stabilized as $\mathrm{K}_{2} \mathrm{Ce}_{2} \mathrm{O}_{4}\left(\mathrm{~K}_{2} \mathrm{O} \cdot \mathrm{Ce}_{2} \mathrm{O}_{3}\right)$ on the top layers of ceria support.

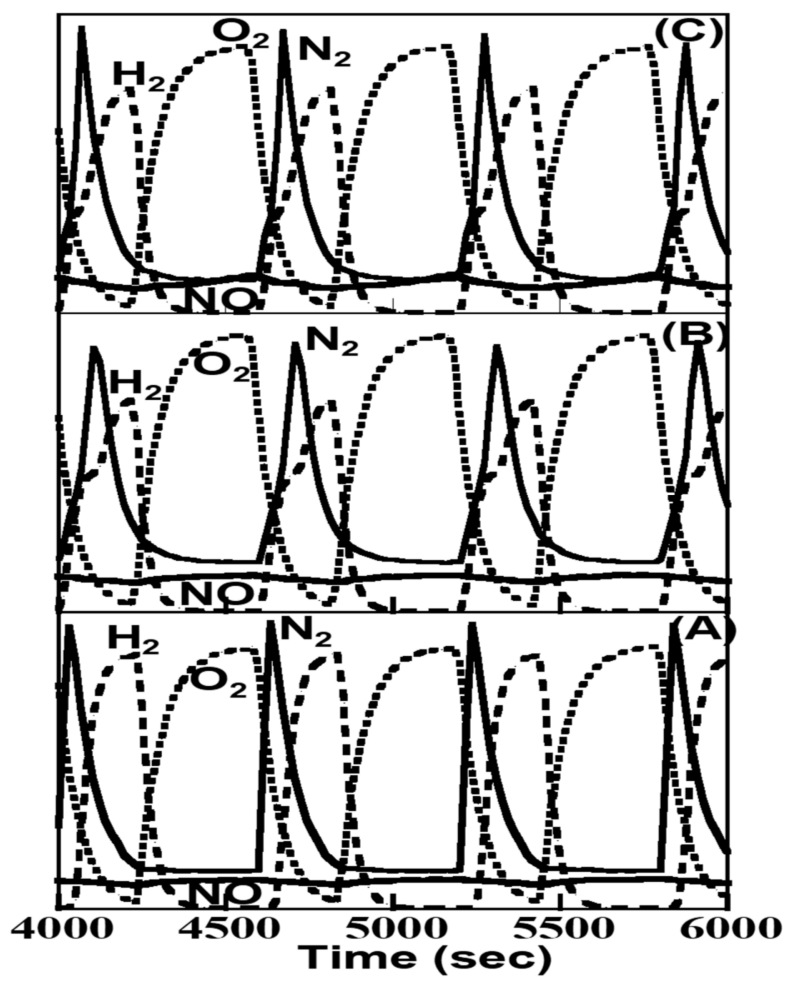

Figure 11. Lean-rich cycles at $350{ }^{\circ} \mathrm{C}$; (A) $\mathrm{Pt}(0.08)-3.5 \mathrm{~K} / \mathrm{CeO}_{2},(\mathbf{B}) \mathrm{Cu}(0.88) 1.3 \mathrm{~K} / \mathrm{CeO}_{2},(\mathbf{C}) \mathrm{Co}(0.88)$ $-1.3 \mathrm{~K} / \mathrm{CeO}_{2}$.

Table 6. Binding-energy $(\mathrm{eV})$ changes during $\mathrm{NO}_{\mathrm{x}}$ stored and reduction processes of $\mathrm{Pt}-2.5 \mathrm{~K} / \mathrm{CeO}_{2}$ and $\mathrm{Cu}-1.3 \mathrm{~K} / \mathrm{CeO}$ by in situ XPS.

\begin{tabular}{|c|c|c|c|c|c|c|c|}
\hline Catalysts & Condition & $\operatorname{Pt} 4 f_{7 / 2}$ & $\mathrm{Cu} 2 \mathrm{p}_{3 / 2}$ & $\mathrm{~K} 2 \mathrm{p}_{3 / 2}$ & $\mathrm{Ce} 3 d_{5 / 2}$ & N 1s & O 1s \\
\hline & reference & 71.0 & 932.7 & 292.7 & 883.1 & 398.1 & 533.2 \\
\hline $\mathrm{Pt} / \mathrm{KNO}_{3}$ & $\mathrm{NO}_{\mathrm{x}}$ stored & $72.3(5)$ & & $292.7(0.3)$ & $889.0(1.2)$ & 407.1 & $532.6,529.0$ \\
\hline$/ \mathrm{CeO}_{2}$ & $\mathrm{H}_{2}$ reduced & $70.6(1)$ & & $293.6(1)$ & $885.6(1)$ & - & $531.6,529.0$ \\
\hline $\mathrm{Cu} / \mathrm{KNO}_{3}$ & $\mathrm{NO}_{x}$ stored & & 933.7 (10) & $292.7(0.1)$ & $889.0(2.5)$ & 406.9 & $532.5,529.0$ \\
\hline$/ \mathrm{CeO}_{2}$ & $\mathrm{H}_{2}$ reduced & & $932.6(1)$ & $293.6(1)$ & $885.6(1)$ & & $531.7,529.0$ \\
\hline
\end{tabular}

$\mathrm{Cu} / \mathrm{KNO}_{3} / \mathrm{CeO}_{2}$ and $\mathrm{Co} / \mathrm{KNO}_{3} / \mathrm{CeO}_{2}$ catalysts exhibit excellent NSR behavior comparable with $\mathrm{Pt} / \mathrm{KNO}_{3} / \mathrm{CeO}_{2}$, which is desirable for practical use by substituting a precious metal with base metals. Facile $\mathrm{K}^{+}$transfer through the subsurface layers of $\mathrm{CeO}_{2}$ may be responsible for these superior catalytic performances.

2.1.5. Preparation of Nanoporous Nickel(II) Phosphate VSB-5 and Their Adsorption and Catalytic Behavior in NO-CO Reactions

VSB-5 can be synthesized between pH7.3 and 11.0 and over a wide range of $\mathrm{Ni} / \mathrm{P}$ ratios and concentrations, employing various organic amines or inorganic basic salts, or even with aq. $\mathrm{NH}_{3}$ as basic reagents. They exhibit quite similar XRD patterns, with the molecular formula of $\mathrm{Ni}_{20}\left[(\mathrm{OH})_{12}\left(\mathrm{H}_{2} \mathrm{O}\right)_{6}\right]\left[\left(\mathrm{HPO}_{4}\right)_{8}\left(\mathrm{PO}_{4}\right)_{4}\right] \cdot 12 \mathrm{H}_{2} \mathrm{O}$, although their crystal morphologies and inner surface structure of micropores seem to be rather different, with 
various preparation conditions. In the present study, we prepared two kinds of catalysts, VSB-5(TEA) and VSB-5 $\left(\mathrm{NH}_{3}\right)$, by employing two extremely different basic reagents, triethylamine (TEA) and $\mathrm{NH}_{3}$. Changes to their morphology and pore structures were studied by $\mathrm{N}_{2}$ and $\mathrm{CO}$ physisorption at $77 \mathrm{~K}, \mathrm{NO}$ and $\mathrm{CO}$ adsorption at higher temperatures, and the catalytic reduction of $\mathrm{NO}$ by $\mathrm{CO}$ at $323-573 \mathrm{~K}$. The effect of $\mathrm{NaOH}$ treatment and the effects of substituting $\mathrm{Ni}$ with $\mathrm{Co}$ and $\mathrm{Fe}$ ions were investigated on $\mathrm{NO}$ adsorption and catalytic behavior of NO-CO reaction. The role of pores and the mechanism of NO-CO reaction were investigated by employing FT-IR spectroscopy.

The results of various catalyst characterizations are summarized in Table 7 . The surface area of VSB-5 (TEA) $\left(15.0 \mathrm{~m}^{2} \mathrm{~g}^{-1}\right)$ estimated from $\mathrm{N}_{2}$ physisorption was abnormally small compared with that of VSB-5 $\left(\mathrm{NH}_{3}\right)\left(318.0 \mathrm{~m}^{2} \mathrm{~g}^{-1}\right)$, suggesting that the end of needle-like crystals of VSB-5(TEA) must be blocked by large amounts of phosphate anions, along with the fringe of the end. After $\mathrm{NaOH}$ treatment, its surface area increased two-fold due to the removal of end-capped phosphate anions from the fringe. In the case of VSB-5 $\left(\mathrm{NH}_{3}\right)$, the surface area decreased by $1 / 3$ by $\mathrm{NaOH}$ treatment.

Table 7. Surface Area, adsorption amount, $\mathrm{P} / \mathrm{Ni}$ ratios and initial rates of the reaction at $523 \mathrm{~K}$.

\begin{tabular}{|c|c|c|c|c|c|c|c|c|c|}
\hline \multirow{2}{*}{ Bases (Treat.) } & \multirow{2}{*}{$\begin{array}{c}\text { S.A. } \\
\mathrm{m}^{2} \mathrm{~g}^{-1}\end{array}$} & \multicolumn{2}{|c|}{ Ads.amt. (77 K) } & \multicolumn{2}{|c|}{ NO(a).amt. $\left(\mathrm{cm}^{3} \mathrm{~g}^{-1}\right)$} & \multirow{2}{*}{$\begin{array}{c}\text { SEM/ } \\
\text { EDX } \\
\text { P/Ni }\end{array}$} & \multicolumn{3}{|c|}{ NO-CO Initial Rate $\left(10^{-7} \mathrm{~mol} / \mathrm{min}^{-1}\right)$} \\
\hline & & $\mathbf{N}_{2}$ & $\mathrm{CO}$ & $293 \mathrm{~K}$ & $353 \mathrm{~K}$ & & $\mathrm{CO}_{2}$ & $\mathrm{~N}_{2} \mathrm{O}$ & $\mathbf{N}_{2}$ \\
\hline VSB-5(TEA) & 15.0 & 2.5 & 3.8 & 4.7 & 4.4 & 0.595 & 1.4 & 2.5 & 1.0 \\
\hline VSB-5 $\left(\mathrm{NH}_{3}\right)$ & 318.0 & 93.5 & 106.0 & 36.1 & 35.3 & 0.625 & 3.0 & 3.0 & 2.5 \\
\hline TEA(NaOH treat.) & 28.4 & 5.8 & 13.5 & 16.0 & 15.0 & 0.718 & 14.0 & 13.0 & 2.5 \\
\hline $\mathrm{NH}_{3}$ (NaOH treat.) & 108.0 & 32.1 & 36.0 & 12.6 & 12.3 & 0.477 & 20.0 & 14.0 & 33.0 \\
\hline
\end{tabular}

Figure 12 shows SEM photos of various VSB- 5 before and after $\mathrm{NaOH}$ treatment. The crystal size of VSB-5 (TEA) was one order of magnitude larger than that of VSB $-5\left(\mathrm{NH}_{3}\right)$, the structure of which did not change much by $\mathrm{NaOH}$ treatment. However, in the case of VSB-5 $\left(\mathrm{NH}_{3}\right)$, an apparent collapse of the morphology began to take place, which could be the reason for the decrease in surface area accompanied by the considerable decrease in $\mathrm{P} / \mathrm{Ni}$ ratio in SEM/EDX measurements.
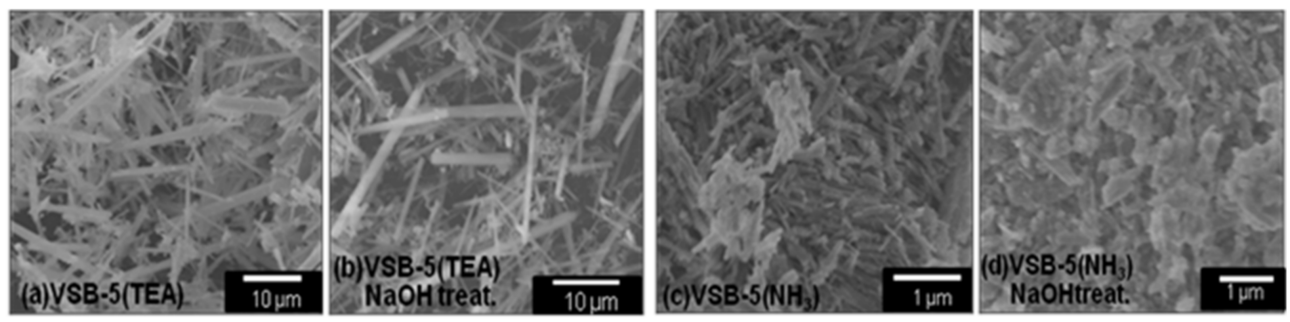

Figure 12. SEM photos of VSB-5 before and after $\mathrm{NaOH}$ treatment.

Figure 13 shows the adsorption isotherms of NO at $353 \mathrm{~K}$ over VSB-5(TEA) and VSB$5\left(\mathrm{NH}_{3}\right)$ before and after $\mathrm{NaOH}$ treatment. The rate of $\mathrm{NO}$ adsorption (solid line) was rather slow over all the catalysts investigated. Especially in the case of VSB-5(TEA), it required a few days to reach equilibrium of adsorption. This may also correspond to the assumption that the end of the crystal must be blocked. The rate of NO desorption was even slower (broken line), and a certain hysteresis phenomenon was observed between adsorption and desorption curves. As summarized in Table 7, the extrapolated amount of adsorbed $\mathrm{NO}$ was correlated well to the surface area of VSB-5, although almost independent of the adsorption temperatures, indicating a strong and activated NO adsorption. 


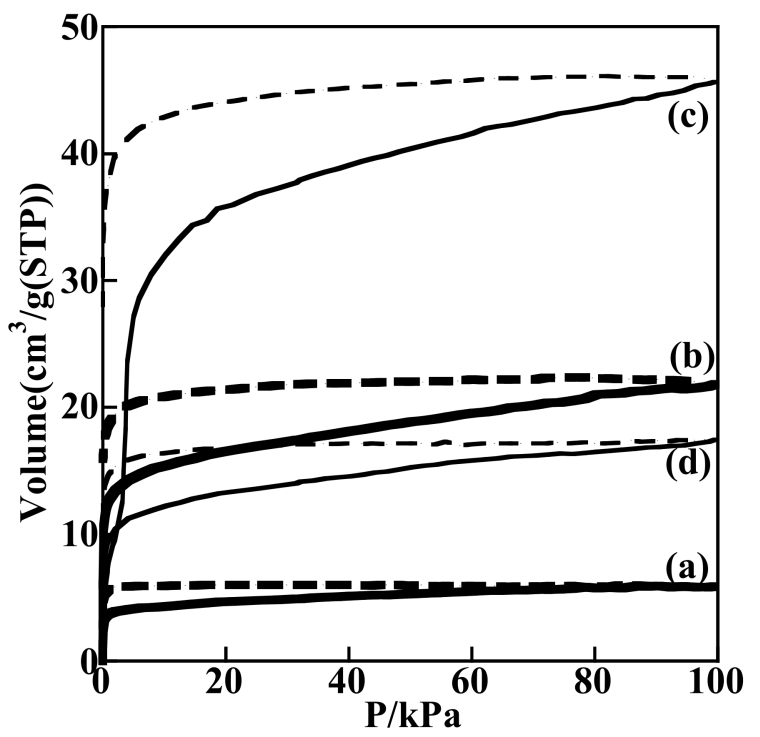

Figure 13. Adsorption isotherms of NO at $353 \mathrm{~K}$, (a) VSB-5(TEA), (b) VSB-5(TEA)NaOH.

It is interesting to note that the effect of $\mathrm{NaOH}$ treatment for $\mathrm{NO}$ adsorption was completely opposite between VSB-5(TEA) and VSB-5 $\left(\mathrm{NH}_{3}\right)$. In the former case, the amount of $\mathrm{NO}$ adsorption increased by three times, whereas it decreased by half in the latter case, which corresponds well to the changes of $\mathrm{p} / \mathrm{Ni}$ ratios by $\mathrm{NaOH}$ treatment as follows: from 0.595 to 0.718 in the former case and from 0.625 to 0.477 in the latter. Based on these experimental results, it is reasonable to suppose that there is a strong electronic interaction between adsorbed NO and phosphate anions inside the micropores. In the last columns of Table 7, initial rates of product formation were summarized in NO-CO reactions over various VSB- 5 catalysts at $523 \mathrm{~K}$. At the initial stage of the reaction, the main products were $\mathrm{CO}_{2}$ and $\mathrm{N}_{2} \mathrm{O}$, with a lower amount of $\mathrm{N}_{2}$, indicating the successive reduction mechanism of $\mathrm{NO}$ into $\mathrm{N}_{2}$ through an $\mathrm{N}_{2} \mathrm{O}$ intermediate. After $\mathrm{NaOH}$ treatment, the initial rates increased by nearly one order of magnitude, indicating the increase in active sites by $\mathrm{NaOH}$ treatment.

Figure 14 shows the time courses of NO-CO reaction over VSB-5(TEA) together with $20 \mathrm{~mol} \%$ Co- and Fe-substituted catalysts at $523 \mathrm{~K}$. Over Co-substituted VSB-5, the reaction rate was enhanced several times, and $\mathrm{N}_{2} \mathrm{O}$ was formed quickly at the initial stage, showing maximum at $30 \mathrm{~min}$. After that, the amount of $\mathrm{N}_{2}$ was increased with the decrease in $\mathrm{N}_{2} \mathrm{O}$, indicating the successive reduction mechanism. The profile of time course was completely different in the case Fe-substituted VSB-5, and $\mathrm{N}_{2}$ was the main product from the beginning, with a small amount of $\mathrm{N}_{2} \mathrm{O}$, indicating the operation of a direct reduction pathway of $\mathrm{NO}$ into $\mathrm{N}_{2}$. 


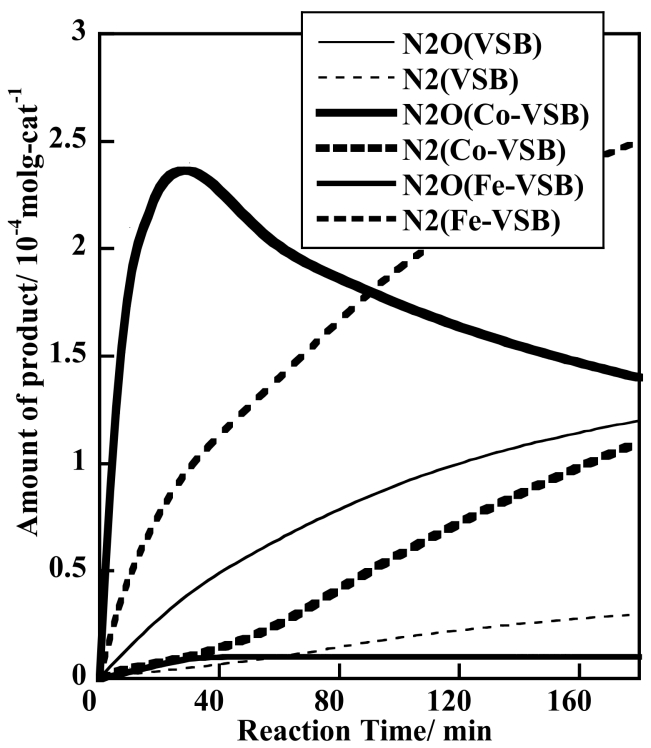

Figure 14. Time courses of NO-CO reaction at $523 \mathrm{~K}$.

Two kinds of VSB-5 were prepared by employing TEA and $\mathrm{NH}_{3}$ as bases. The crystal size of VSB-5 (TEA) was one order of magnitude larger than that of VSB-5( $\left.\mathrm{NH}_{3}\right)$, with a surface area one order of magnitude smaller. The end of the former crystal must be blocked by large amounts of phosphate anions, which were partially removed by $\mathrm{NaOH}$ treatment. Adsorption and desorption isotherms of NO at 293-353 K showed the hysteresis curves, indicating that the inner space of micropores must be crowded by phosphate anions. However, once NO molecules can get into the pores, they may be stabilized by a certain electronic interaction with phosphate anions. These catalysts were very active for NO-CO reaction at 323-573 $\mathrm{K}$ with the successive reduction mechanism. Substitution of $\mathrm{Ni}^{2+}$ ions with $\mathrm{Co}^{2+}$ and $\mathrm{Fe}^{2+}$ largely enhanced their catalytic activity, indicating that coordinately unsaturated metal ${ }^{2+}$ ions in the framework of VSB-5 are the active sites for this catalytic reaction.

2.1.6. Unusual Storage of $\mathrm{NO}$ and Its Efficient Removal by Various Reducing Agents inside One-Dimensional Micropores of Nickel (II) Phosphate VSB-5 Catalysts

Nickel (II) phosphate VSB-5 is a novel microporous material with a 24-ring openframework of $\mathrm{NiO}_{6}$ octahedra (1-D channels), which has outstanding properties and high thermal stability. In the present study, we prepared two kinds of catalysts, VSB-5(TEA), VSB-5 $\left(\mathrm{NH}_{3}\right)$, by employing extremely different basic reagents, trimethylamine (TEA) and ammonia $\left(\mathrm{NH}_{3}\right)$. Substitution of $\mathrm{Ni}^{2+}$ with other metal ${ }^{2+}$ ions $(\mathrm{V}, \mathrm{Fe}, \mathrm{Co})$ was carried out to prepare efficient catalysts for $\mathrm{NO}$ storage and removal by various reducing agents, such as $\mathrm{H}_{2}, \mathrm{CO}, \mathrm{NH}_{3}$, and $\mathrm{CH}_{4}$.

As summarized in Table 8, the surface area of VSB-5 (TEA) estimated from $\mathrm{N}_{2}$ physisorption was very small compared with that of VSB-5 $\left(\mathrm{NH}_{3}\right)$, suggesting that the end of needle-like crystals of VSB-5(TEA) must be blocked by large amounts of phosphate anions, along with the fringe of the end. The rates of both NO adsorption and desorption were very slow over both catalysts, and a certain hysteresis phenomenon was observed between adsorption and desorption curves, suggesting that the inner space of micropores must be crowded by phosphate anions. However, once NO molecules can get into the pores, they may be stabilized by a certain electronic interaction with phosphate anions and activated for catalytic reactions. 
Table 8. Surface area, adsorption amounts, and initial rates of various reactions at $523 \mathrm{~K}$.

\begin{tabular}{|c|c|c|c|c|c|c|c|c|c|}
\hline \multirow{3}{*}{ Catalysts } & \multirow{3}{*}{$\begin{array}{c}\text { S.A. } \\
\mathrm{m}^{2} \mathrm{~g}^{-1}\end{array}$} & \multicolumn{2}{|c|}{ NO(a).amt. $\left(\mathrm{cm}^{3} \mathrm{~g}^{-1}\right)$} & \multicolumn{6}{|c|}{ Initial Rates of Product Formation $\left(10^{-7} \mathrm{~mol} / \mathrm{min}^{-1}\right)$} \\
\hline & & $293 \mathrm{~K}$ & $353 \mathrm{~K}$ & \multicolumn{2}{|c|}{ NO- $\mathrm{H}_{2}$ Reaction } & \multicolumn{2}{|c|}{ NO-CO Reaction } & \multicolumn{2}{|c|}{ NO-CH 4 Reaction } \\
\hline & & & & $\mathrm{N}_{2}$ & $\mathrm{~N}_{2} \mathrm{O}$ & $\mathrm{N}_{2}$ & $\mathrm{~N}_{2} \mathrm{O}$ & $\mathrm{N}_{2}\left(\mathrm{~N}_{2} \mathrm{O}\right)$ & $\mathrm{CH}_{3} \mathrm{CN}$ \\
\hline VSB-5(TEA) & 15.0 & 4.7 & 4.4 & 14.3 & 2.3 & $3 . \overline{5}$ & 0.8 & 0.6 & 0.2 \\
\hline VSB-5 $\left(\mathrm{NH}_{3}\right)$ & 318.0 & 36.1 & 35.3 & 18.6 & 3.5 & 5.8 & 1.4 & 1.3 & 0.5 \\
\hline
\end{tabular}

In the last three columns of the table, initial rates of product formation are summarized during $\mathrm{NO}-\mathrm{H}_{2}, \mathrm{NO}-\mathrm{CO}$, and $\mathrm{NO}-\mathrm{CH}_{4}$ reactions over both catalysts at $523 \mathrm{~K}$. In the case of $\mathrm{NO}-\mathrm{H}_{2}$ and NO-CO reactions, the main products were $\mathrm{N}_{2}, \mathrm{CO}_{2}$ and $\mathrm{H}_{2} \mathrm{O}$, with a lower amount of $\mathrm{N}_{2} \mathrm{O}$. In the NO- $\mathrm{CH}_{4}$ reaction, a considerable amount of $\mathrm{CH}_{3} \mathrm{CN}$ was formed additionally. Substitution of $\mathrm{Ni}^{2+}$ ions with $\mathrm{V}^{2+}, \mathrm{Fe}^{2+}$, or $\mathrm{Co}^{2+}$ enhanced their catalytic activities by more than one order of magnitude, indicating that well dispersed, coordinately unsaturated metal ${ }^{2+}$ ions in the framework of VSB- 5 are active for these catalytic reactions.

2.1.7. Effect of $\mathrm{Co}(\mathrm{II}), \mathrm{Fe}(\mathrm{II})$, and V(II) Substitution upon Unusual NOx Storage and Efficient Removal by Various Reducing Agents inside 1-D Channels of Microporous Nickel (II) Phosphate Catalysts

As already shown in Table 8, the surface area of VSB-5 (TEA) $\left(15.0 \mathrm{~m}^{2} \mathrm{~g}^{-1}\right)$ estimated from $\mathrm{N}_{2}$ physisorption was abnormally small compared with that of VSB-5 $\left(\mathrm{NH}_{3}\right)$ $\left(318.0 \mathrm{~m}^{2} \mathrm{~g}^{-1}\right)$, suggesting that the end of needle-like crystals of VSB-5(TEA) must be blocked by large amounts of phosphate anions, along with the fringe of the end. In the case of VSB- $5\left(\mathrm{NH}_{3}\right)$, the surface area decreased by $1 / 3$ by $\mathrm{NaOH}$ treatment. The SEM photos of various VSB-5 showed that the crystal size of VSB-5(TEA) was one order of magnitude larger than that of VSB-5 $\left(\mathrm{NH}_{3}\right)$. On the other hand, XRD patterns of all the samples did not change much, showing characteristic diffraction patterns assignable to typical VSB-5. The rate of NO adsorption was rather slow over all the catalysts investigated. Especially in the case of VSB-5(TEA), it required a few days to reach equilibrium of adsorption. The rate of NO desorption was even slower, and a certain hysteresis phenomenon was observed between adsorption and desorption curves. As can be seen in the table, the extrapolated amount of adsorbed NO was correlated well to the surface area of VSB-5, although almost independent of the adsorption temperatures, indicating a strong and activated NO adsorption in these temperature ranges. From these results, it is reasonable to suppose that there is a strong electronic interaction between adsorbed NO and phosphate anions inside the micropores. In the last columns of the table, initial rates of product formation are summarized in NO-CO reactions over various VSB- 5 catalysts at $523 \mathrm{~K}$. At the initial stage of the reaction, the main products were $\mathrm{CO}_{2}$ and $\mathrm{N}_{2} \mathrm{O}$, with lower amounts of $\mathrm{N}_{2}$, indicating the successive reduction mechanism of $\mathrm{NO}$ into $\mathrm{N}_{2}$ through $\mathrm{N}_{2} \mathrm{O}$ intermediate. Figure 15 shows the time courses of NO-CO reactions over VSB-5(TEA), together with $20 \mathrm{~mol} \% \mathrm{Co}$ - and Fe-substituted catalysts at $523 \mathrm{~K}$. Over Co-substituted VSB-5, the reaction rate was enhanced several times, and $\mathrm{N}_{2} \mathrm{O}$ was formed quickly at the initial stage, showing its maximum at $30 \mathrm{~min}$. After that, the amount of $\mathrm{N}_{2}$ was increased with the decrease in $\mathrm{N}_{2} \mathrm{O}$, indicating the successive reduction mechanism. The profile of time course was completely different in the case Fe-substituted VSB-5, and $\mathrm{N}_{2}$ was the main product from the beginning, with a small amount of $\mathrm{N}_{2} \mathrm{O}$, indicating the operation of a direct reduction pathway of NO into $\mathrm{N}_{2}$. Two kinds of VSB- 5 were prepared by employing TEA and $\mathrm{NH}_{3}$ as bases. The crystal size of VSB-5(TEA) was one order of magnitude larger than that of VSB-5 $\left(\mathrm{NH}_{3}\right)$, with a surface area one order of magnitude smaller. Adsorption and desorption isotherms of $\mathrm{NO}$ at 293-353 K showed hysteresis curves, indicating that the inner space of micropores must be crowded by phosphate anions. However, once NO molecules can get into the pores, they may be stabilized by a certain electronic interaction with phosphate anions. These catalysts were very active for NO-CO reactions at $323-573 \mathrm{~K}$ with the successive reduction mechanism. Substitution of $\mathrm{Ni}^{2+}$ ions with $\mathrm{Co}^{2+}$ and $\mathrm{Fe}^{2+}$ 
largely enhanced their catalytic activity, indicating that coordinately unsaturated metal ${ }^{2+}$ ions in the framework of VSB-5 are the active sites for this catalytic reaction.

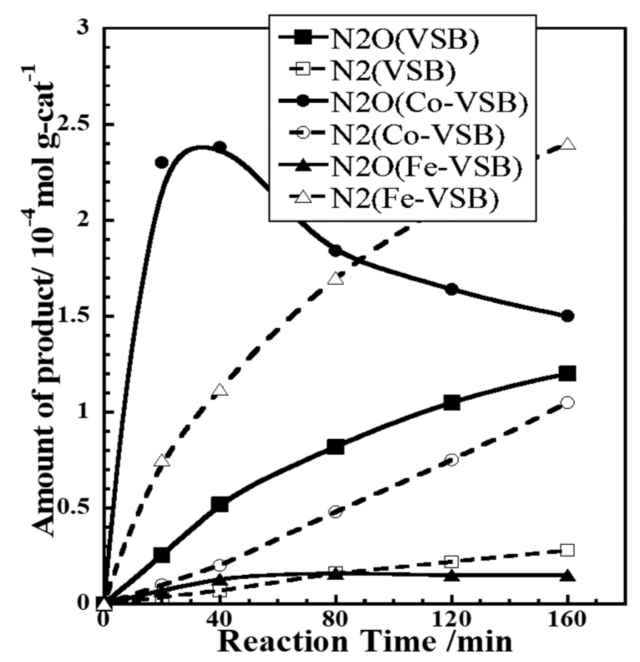

Figure 15. Time course of NO-CO reaction.

\subsubsection{Catalytic Reduction of $\mathrm{NO}$ by $\mathrm{H}_{2}$ over Co-Substituted Nanoporous $\mathrm{Ni}$} Phosphates, VSB-5

The removal of NO remains an urgent environmental problem. Great effort has been devoted to the development of new efficient catalysts to realize practical applications and to understand an intrinsic reaction mechanism. Recently, nickel phosphate VSB-5 and its cobalt substituent have been synthesized, possessing one-dimensional open frameworks $(\mathrm{D}=1.1 \mathrm{~nm})$ and exhibiting some interesting catalytic behaviors. In the present study, we first studied the catalytic reduction of $\mathrm{NO}$ by $\mathrm{H}_{2}$ over these materials, applying kinetic investigation as well as FT-IR observation during the reaction.

Nickel phosphate, VSB-5, and cobalt- (10-20\% molar ratio) substituted Ni-phosphate (Co-VSB-5) were synthesized in hydrothermal conditions according to the literature. The catalytic $\mathrm{NO}-\mathrm{H}_{2}$ reaction (10 Torr $(0.18 \mathrm{mmol})$ each, $200 \mathrm{mg}$ catalyst) was carried out in a closed gas-circulation system with an online analysis by GC. FT-IR spectroscopy was employed to observe adsorbed species during the reaction. The catalysts were characterized by XRD, XPS, TEM, TG, TPD, and $\mathrm{N}_{2}$ adsorption techniques.

Co-VSB- 5 has a large amount of water molecules in its pores, and to obtain the catalytic activity, it is necessary to remove a certain amount of water molecules by evacuation at higher temperatures (Figure 16).

Accordingly, the catalyst was first evacuated at $300^{\circ} \mathrm{C}$ for $20 \mathrm{hrs}$ before reaction. As shown in Figure 17, the catalytic activity of VSB-5 for NO- $\mathrm{H}_{2}$ reaction was low. However, substitution of $\mathrm{Ni}$ with $\mathrm{Co}$ enhanced the reaction rates by more than one order of magnitude. The amount of adsorbed NO was also increased by higher-temperature evacuation up to $350{ }^{\circ} \mathrm{C}$ (Figure 18), which corresponded well to the catalytic activities.

It is worth noting that $20 \mathrm{~mol} \% \mathrm{Co}-\mathrm{VSB}-5$ catalysts were very active for the hydrogen dissociation process, and $\mathrm{H}_{2}-\mathrm{D}_{2}$ exchange reaction took place even at $-80^{\circ} \mathrm{C}$, as shown in Figure 19. An HZ (Co-VSB-5)- $\mathrm{D}_{2}$ hydrogen exchange reaction also took place around 150 ${ }^{\circ} \mathrm{C}$, suggesting the incorporation of surface $\mathrm{OH}$ or $\mathrm{HPO}_{3}$ groups into the reaction with NO . As shown in Figure 19C, hydrogen dissociation was significantly inhibited by the presence of $\mathrm{NO}$, suggesting competitive adsorption of $\mathrm{NO}$ and $\mathrm{H}_{2}$ at the active sites. 


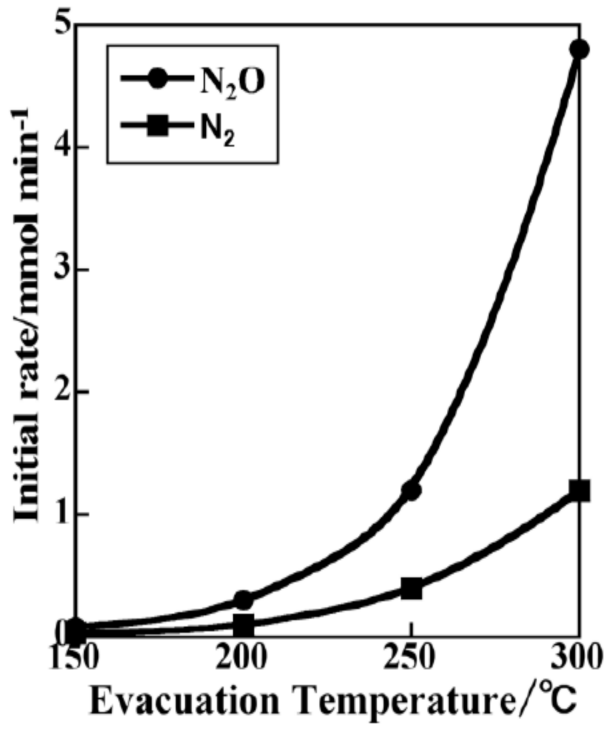

Figure 16. Evacuation temperature versus initial rates at $200^{\circ} \mathrm{C}$.

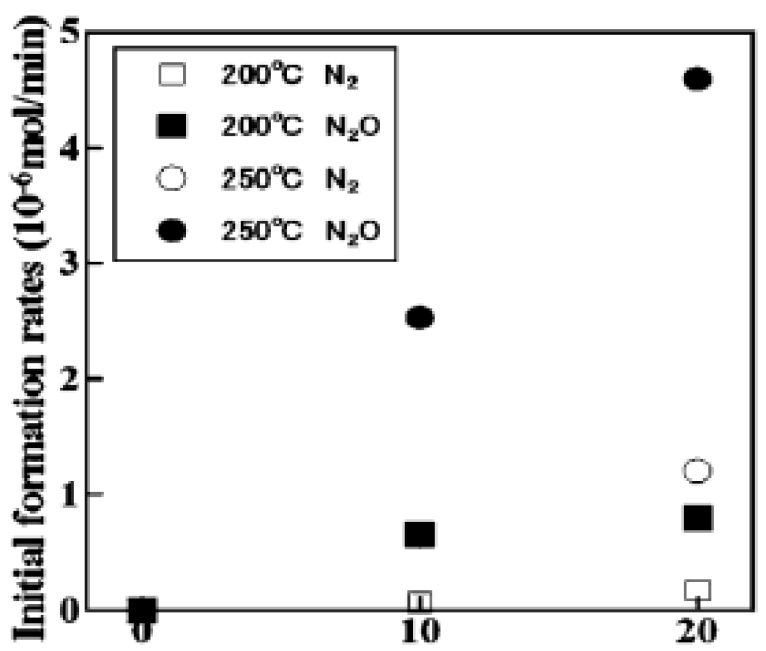

Figure 17. Substituted $\mathrm{Co}^{2+}$ amount versus initial rates at $200{ }^{\circ} \mathrm{C}$.

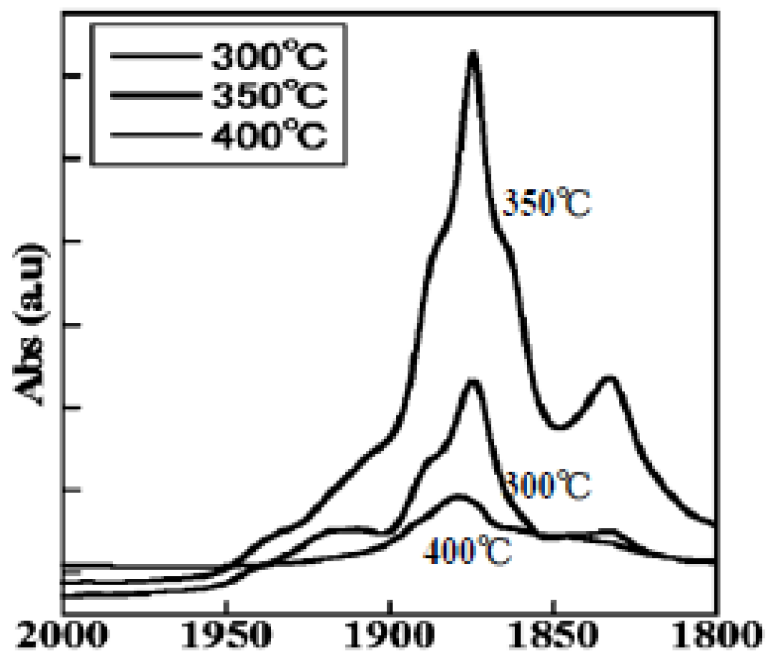

Figure 18. FT-IR spectra of NOa) at RT after various temp. evacuation over diluted $20 \mathrm{~mol} \%$ Co-VSB-5. 

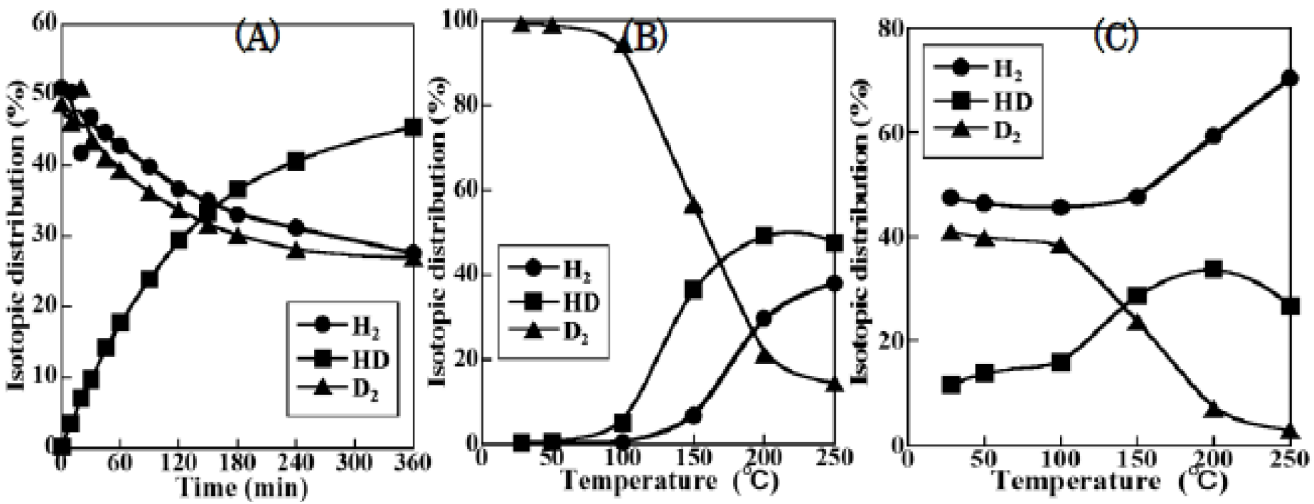

Figure 19. (A) $\mathrm{H}_{2}-\mathrm{D}_{2}$ exchange at $-80{ }^{\circ} \mathrm{C},(\mathbf{B}) \mathrm{HZ}-\mathrm{D}_{2}$ exchange and (C) $\mathrm{H}_{2}-\mathrm{D}_{2}$ exchange (in the presence of NO), over $20 \mathrm{~mol} \% \mathrm{Co}-\mathrm{VSB}-5$ catalysts.

\section{Mechanistic Investigation and Design of NSR Catalysts}

As is well known, conventional three-way catalysts (TWC) are highly efficient in reducing $\mathrm{NO}_{\mathrm{x}}, \mathrm{CO}$, and unburned hydrocarbon emissions, though only within a narrow window region around stoichiometric air/fuel ratio air/fuel $(\mathrm{A} / \mathrm{F}=14.7)$. However, under lean-burn conditions, which are favorable to reduce $\mathrm{CO}_{2}$ emissions and to realize high fuel-efficiency, $\mathrm{NO}_{\mathrm{x}}$ emissions fall to very low levels in the case of TWA catalysts. To improve this situation, $\mathrm{NO}_{\mathrm{x}}$ storage-reduction catalysts (SR) are promising. Effective $\mathrm{NO}_{\mathrm{x}}$ removal techniques for lean-burn exhaust are eagerly desired, and $\mathrm{NO}_{x}$ storage-reduction (NRS) catalysts have been recognized as promising. In the case of the original Pt-Ba/ $\mathrm{Al}_{2} \mathrm{O}_{3}$ catalysts first reported by Toyota's research group, an NOx storage-reduction mechanism can be formulated as follows:

$$
\begin{gathered}
\text { Lean-burn condition; } 2 \mathrm{NO}+\mathrm{O}_{2} \rightarrow 2 \mathrm{NO}_{2} \text { (on Pt), } 2 \mathrm{NO}_{2}+\mathrm{BaO} \rightarrow \mathrm{Ba}\left(\mathrm{NO}_{3}\right)_{2} \\
\text { Rich-burn condition; } \mathrm{Ba}\left(\mathrm{NO}_{3}\right)_{2}+4 \mathrm{H}_{2} \rightarrow \mathrm{N}_{2}+4 \mathrm{H}_{2} \mathrm{O}+\mathrm{BaO} .
\end{gathered}
$$

NSR catalysts are composed three essential elements: (1) a high-surface-area metal oxide, such as $\mathrm{Al}_{2} \mathrm{O}_{3}$, as a support, (2) basic elements, such as $\mathrm{Ba}$ or $\mathrm{K}$, for $\mathrm{NO}_{\mathrm{x}}$ storage sites, and (3) precious-metal redox sites, such as $\mathrm{Pt}, \mathrm{Pd}$, and $\mathrm{Rh}$, for the redox reaction for oxidizing $\mathrm{NO}$ to $\mathrm{NO}_{2}$ and reducing stored $\mathrm{NO}_{x}$ to $\mathrm{N}_{2}$ by various reductants. Correspondingly, the following three factors may be important as efficient NSR catalysts in Pt-alkali metal/metal oxide support systems: (a) smaller Pt particles for NO oxidation and (alkali metal) $-\mathrm{NO}_{3}$ reduction, (b) facile migration of alkali cations from and back to subsurface layers during redox cycles, and (c) the existence of a certain surface structure to maintain high dispersion of alkali cations. In this section, detailed NSR mechanisms over various nanostructured catalysts will be discussed by changing these essential factors.

\subsection{Transition-Metal Redox Sites}

Pt plays several key roles in the NOx storage/reduction reaction steps, such as NO oxidation under lean-burn conditions, NOx storage under lean-burn conditions, and NOx reduction under rich-burn conditions. As mentioned in the previous section, we extended our KTN catalysts to a $\mathrm{KNO}_{3}$-added $\mathrm{Pt} / \mathrm{CeO}_{2}$ system, which also exhibited high $\mathrm{NO}_{\mathrm{x}}$ storage capacity and good redox cycle behavior as NSR catalysts. Moreover, we substituted $\mathrm{Pt}$ with $\mathrm{Cu}$ or $\mathrm{Co}$ and compared their catalytic behaviors by applying a kinetic investigation, as well as in situ XPS and FT-IR measurements during the reaction.

$\mathrm{Cu} / \mathrm{KNO}_{3} / \mathrm{CeO}_{2}$ and $\mathrm{Co} / \mathrm{KNO}_{3} / \mathrm{CeO}_{2}$ catalysts exhibit excellent NSR behavior comparable with $\mathrm{Pt} / \mathrm{KNO}_{3} / \mathrm{CeO}_{2}$, which is desirable for practical use by substituting a precious metal with base metals. Facile $\mathrm{K}^{+}$transfer through the subsurface layers of $\mathrm{CeO}_{2}$ may be responsible for these superior catalytic performances. Accordingly, under rich conditions, $\mathrm{K}^{+}$may be stabilized as $\mathrm{K}_{2} \mathrm{Ce}_{2} \mathrm{O}_{4}\left(\mathrm{~K}_{2} \mathrm{O} \cdot \mathrm{Ce}_{2} \mathrm{O}_{3}\right)$ on the top layers of ceria support, and phase transfer between $\mathrm{PtCeO}_{3}(\mathrm{lean})$ and $\mathrm{K}_{2} \mathrm{Ce}_{2} \mathrm{O}_{4}$ (rich) surface nanocomposites is 
responsible for high capacity and durability, which is realized by the facile combination of $\mathrm{Ce}^{3+} \Leftrightarrow \mathrm{Ce}^{4+}$ and $\mathrm{Pt}^{0} \Leftrightarrow \mathrm{Pt}^{2+}$ redox cycles. On the contrary, over $\mathrm{Pt}-\mathrm{K} / \mathrm{ZrO}_{2}$, because of the absence of a $\mathrm{Zr}^{3+} \Leftrightarrow \mathrm{Zr}^{4+}$ redox cycle, sintering of $\mathrm{PtO}_{2}$ (lean) and $\mathrm{K}_{2} \mathrm{O}$ (rich) easily takes place during lean-rich cycles, which causes the deactivation.

\subsection{NOx Trapping Sites}

$\mathrm{BaO}$ is the most commonly studied NOx trapping component among metal oxides, with a major contribution to the overall NOx trapping capacity. Besides the NOx storage step, $\mathrm{BaO}$ also plays a role in the $\mathrm{NO}$ oxidation, NOx release, and NOx reduction steps. Although different metal-oxide supports and precious-metal components affect the functions of $\mathrm{BaO}$ in NSR reactions, in this section, we still focus on the general functions of $\mathrm{BaO}$ and of the $\mathrm{Pt} / \mathrm{BaO} / \mathrm{Al}_{2} \mathrm{O}_{3}$ catalyst in NSR reactions.

(a) NO oxidation step; as reviewed in the previous section, $\mathrm{BaO}$ presents some negative effects in NO oxidation as a result of its blockage of the Pt surface and its stabilization effect on Pt oxides (inactive for NO oxidation).

(b) NOx storage step; because of the complexity of this step, it is difficult to identify and differentiate mechanisms that occurred during the NOx trapping process. Both nitrites and nitrates are detected on the NSR catalyst after NOx trapping. Therefore, it is well accepted that there must be a nitrite route and a nitrate route for the NOx trapping on $\mathrm{BaO}$. Within the nitrite route, it is proposed that $\mathrm{NO}$ is oxidized on $\mathrm{Pt}$ sites and directly trapped by nearby $\mathrm{BaO}$ sites to form $\mathrm{Ba}$ nitrites. The $\mathrm{Ba}$ nitrites are finally oxidized to Ba nitrates. Within the nitrate route, it is proposed that $\mathrm{NO}$ is oxidized to $\mathrm{NO}_{2}$ on Pt sites. $\mathrm{NO}_{2}$ spills over to the $\mathrm{BaO}$ site to form Ba nitrate with the evolution of NO. When Ba loading is high or low, there are more or fewer Ba sites that are close to the $\mathrm{Pt}$ sites, which leads to the predominance of the nitrite route or nitrate route. At high temperatures, no matter whether $\mathrm{NO}$ or $\mathrm{NO}_{2}$ is used as the $\mathrm{NOx}$ precursor, similar $\mathrm{NOx}$ trapping capacity is observed on the $\mathrm{Pt} / \mathrm{BaO} / \mathrm{Al}_{2} \mathrm{O}_{3}$ catalyst. This is because $\mathrm{NO}$ can be easily oxidized to $\mathrm{NO}_{2}$ at high temperatures. However, at low temperatures, the NOx-trapping capacity of $\mathrm{BaO}$ is low when using $\mathrm{NO}$ as a $\mathrm{NOx}$ precursor due to limited $\mathrm{NO}$ oxidation into $\mathrm{NO}_{2}$. With $\mathrm{NOx}$ trapping $\mathrm{BaO}$, the $\mathrm{H}_{2} \mathrm{O}$ and $\mathrm{CO}_{2}$ in the exhaust could react to produce barium hydroxide and carbonate. The thermodynamic stability of $\mathrm{BaCO}_{3}$ is higher than that of $\mathrm{Ba}(\mathrm{OH})_{2}$. In contrast to $\mathrm{BaO}$, in order to trap $\mathrm{NOx}, \mathrm{Ba}(\mathrm{OH})_{2}$ and $\mathrm{BaCO}_{3}$ must decompose first and then react with NOx. Therefore, the presence of $\mathrm{H}_{2} \mathrm{O}$ and $\mathrm{CO}_{2}$ in the exhaust gas phase will affect the rate of NOx trapping. In addition, $\mathrm{CO}_{2}$ decreases more NOx-trapping capacity than $\mathrm{H}_{2} \mathrm{O}$.

(c) NOx release step; the release of NOx is very important for efficient regeneration of NOx-trapping sites and the following NOx reduction process. NOx release is induced by the decomposition of Ba nitrites and Ba nitrates upon high temperature and rich excursion (reductant introduction). The stability of Ba nitrites and Ba nitrates decreases with increasing temperature and decreasing $\mathrm{O}_{2}$ partial pressure, causing their decomposition so as to release NOx. Apart from the reductant gases and $\mathrm{O}_{2}$, the presence of other gases, such as $\mathrm{H}_{2} \mathrm{O}$ and $\mathrm{CO}_{2}$, also affects NOx release during the rich-burn cycle. The presence of $\mathrm{H}_{2} \mathrm{O}$ reduces $\mathrm{NOx}$ release, while $\mathrm{CO}_{2}$ increases $\mathrm{NOx}$ release.

\subsection{Surface Structure for Storage}

In the cases of VSB-5-type NSR catalysts, once NO molecules can get into the pores, they may be stabilized by a certain electronic interaction with phosphate anions. These catalysts were very active for NO-CO reaction at 323-573 K with the successive reduction mechanism. Substitution of $\mathrm{Ni}^{2+}$ ions with $\mathrm{Co}^{2+}$ and $\mathrm{Fe}^{2+}$ largely enhanced their catalytic activity, indicating that coordinately unsaturated metal ${ }^{2+}$ ions in the framework of VSB-5 are the active sites for this catalytic reaction. 


\subsubsection{Adsorption-Desorption Behavior of NO and CO on Nanoporous VSB-5}

A large amount of NO and/or CO can be adsorbed into the pores of VSB-5, and strong and sharp bands were observed by in situ FT-IR investigation. They exhibit unusual behavior in the adsorption and desorption process. The amount of adsorption could be promoted by increasing the adsorption temperature, which could produce more active sites. The adsorption of $\mathrm{CO}$ and $\mathrm{NO}$ is competitive, and the adsorbed $\mathrm{CO}$ may be replaced by NO due to the stronger bonding strength of the latter. In this section, in situ FT-IR and temperature-programmed desorption (TPD) techniques were employed to investigate the adsorption/desorption behaviors of $\mathrm{NO}$ and $\mathrm{CO}$. Following the pretreatment of the sample by $250{ }^{\circ} \mathrm{C}$ evacuation, 30 torr of $\mathrm{NO}$ was introduced, and the spectrum was taken at room temperature, as shown in Figure 20 (RT). Two peaks $\left(1873\right.$ and $\left.1858 \mathrm{~cm}^{-1}\right)$ and a shoulder $\left(1886 \mathrm{~cm}^{-1}\right)$ were observed in the in situ FT-IR spectra. These three bands may be assigned to the mononitrosyl species adsorbed on three kinds of $\mathrm{Ni}^{2+}$ at specific positions corresponding to three kinds of $\mathrm{Ni}$ in the framework of VSB-5. The main peak $\left(1873 \mathrm{~cm}^{-1}\right)$ may be assigned to $\mathrm{NO}$ adsorbed on $\mathrm{Ni}^{2+}$, while the weak peaks at 1858 and $1886 \mathrm{~cm}^{-1}$ may be attributed to the $\mathrm{NO}$ adsorbed on $\mathrm{Ni}^{2-\delta}$ and $\mathrm{Ni}^{2+\delta}$, respectively. The $\mathrm{Ni}^{2-\delta}$ may result from the $\mathrm{Ni}^{2+}$ coordinated with more electrically negative species, such as oxo species, while the $\mathrm{Ni}^{2+\delta}$ may come from the $\mathrm{Ni}^{2+}$ linked with less electrically negative species.

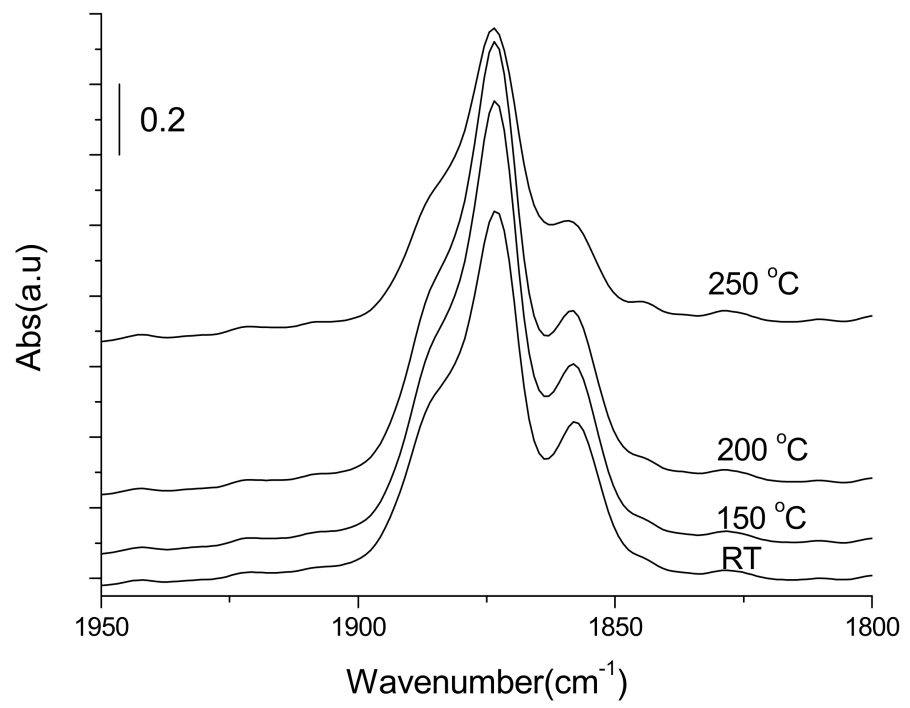

Figure 20. FT-IR spectra of adsorbed NO at various temperatures over VSB-5.

The sample was heated to different temperatures under an NO atmosphere and kept for $30 \mathrm{~min}$ at each temperature. Then, the temperature was lowered to room temperature in the presence of NO, and the FT-IR spectra were recorded, as shown in Figure 20 (150, $200,250{ }^{\circ} \mathrm{C}$ ). The integrated intensity of absorbed species increased about $14 \%$ when the temperature was raised to $150{ }^{\circ} \mathrm{C}$, suggesting that more $\mathrm{NO}$ was adsorbed on some sites at high temperatures, which were inaccessible at lower temperatures. It is known that five kinds of $\mathrm{OH}$ groups exist in the channels of VSB-1 and interact with each other during the heating process. Considering the similarity of the structure, it is reasonable to suppose that the heating process may cause the interactions between $\mathrm{P}-\mathrm{OH}$ groups. These interactions had an influence on the coordination of nickel cations and produced some unsaturated sites, providing more active locations for the adsorption of NO within the channels. However, the integral intensities decreased when the temperature was higher than $200{ }^{\circ} \mathrm{C}$. After heating to $250{ }^{\circ} \mathrm{C}$, the intensity was lower than that at room temperature. This may be caused by the destruction of some $\mathrm{NO}$ adsorption sites during the further heating process. Additionally, decomposition of $\mathrm{NO}$ presented, and the formation of $\mathrm{N}_{2}$ and $\mathrm{N}_{2} \mathrm{O}$ was also observed during the $\mathrm{NO}$ adsorption at higher temperatures in the online analysis of GC. 
Different amounts of $\mathrm{NO}$ with varied pressures were introduced after pretreatment and adsorbed for $30 \mathrm{~min}$ at room temperature. Then, the FT-IR spectra were taken, as shown in Figure 21. Two peaks and a shoulder were observed at 1875, 1858, and $1886 \mathrm{~cm}^{-1}$, respectively, under the pressure of $7 \times 10^{-2}$ torr NO. The intensities of the absorption peaks increased a little with increasing pressure, and the integrated intensity for 30 torr was 1.54 times more than that of $7 \times 10^{-2}$ torr, although there is not much difference between the adsorption at 10 torr and 30 torr. The position of the main band shifted from 1875 to $1873 \mathrm{~cm}^{-1}$ when the pressure was increased to 1 torr and remained unchanged with increasing pressure.

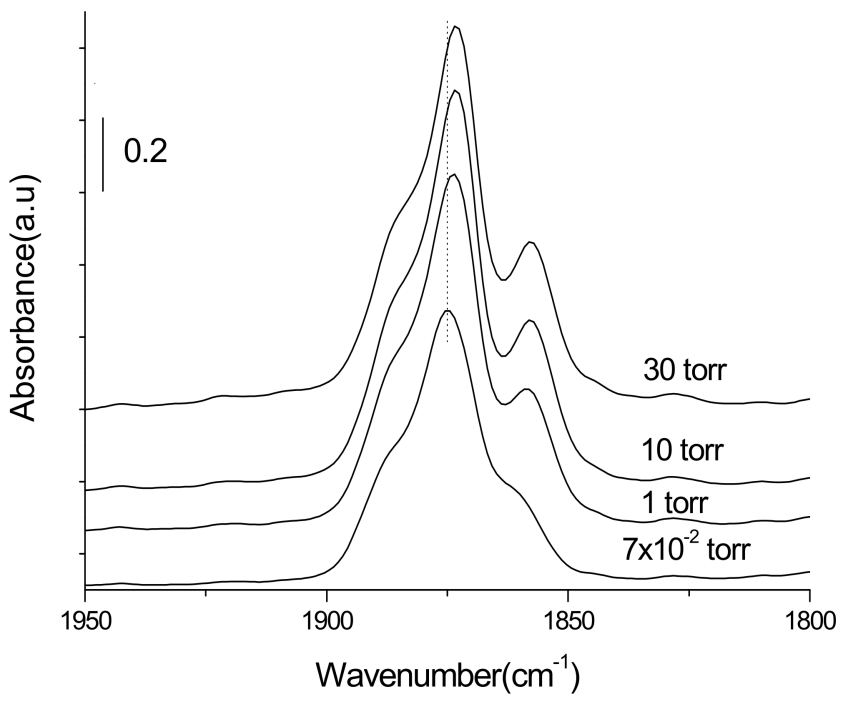

Figure 21. FT-IR spectra of adsorbed NO under various pressures at RT.

This shift suggests that the adsorbed NO species may interact with the surrounding species from the framework of VSB- 5 and form different kinds of mononitrosyl species. It was reported that $\mathrm{NO}$ preferred to form dinitrosyl species on the $\mathrm{Ni}^{2+}$ surface, while no dinitrosyl species were observed in the above experiments. One possible reason may be that the $\mathrm{Ni}^{2+}$ ions were highly occupied, and no more vacancies were available for dinitrosyls. The other possible reason may be the decomposition of dinitrosyl complexes to linear mononitrosyl species at ambient temperature. At the same time, the band at $1858 \mathrm{~cm}^{-1}$ became more obvious and changed into a clear band when the pressure increased to 1 torr. These bands had very narrow full width at half maximum (FWHM), suggesting that the Ni sites were homogeneously distributed, as proposed by the reported literature.

Figure 22 shows the desorption spectra of adsorbed NO after the above heatingup/cooling-down adsorption process. These adsorbed species could be desorbed by evacuation, and more species were removed with the rise of evacuating temperature due to thermal behaviors. The weak band at $1886 \mathrm{~cm}^{-1}$ was less stable and converted to a weaker shoulder after evacuation at $100{ }^{\circ} \mathrm{C}$. A total of $75 \%$ of the integral intensity was lost by evacuating for $30 \mathrm{~min}$ at $150{ }^{\circ} \mathrm{C}$. As for the species adsorbed at room temperature, similar behaviors were observed during the desorption process (spectra not shown). However, the adsorbed species were less stable compared to those adsorbed at high temperatures, and $94 \%$ of integral intensity was lost after evacuating for $30 \mathrm{~min}$ at $150{ }^{\circ} \mathrm{C}$. Complete removal of the species was achieved by evacuation at $200{ }^{\circ} \mathrm{C}$. These results indicate that the species adsorbed at raised temperatures have higher stability, and their stability may come from the components adsorbed at the sites inaccessible at low temperatures. 


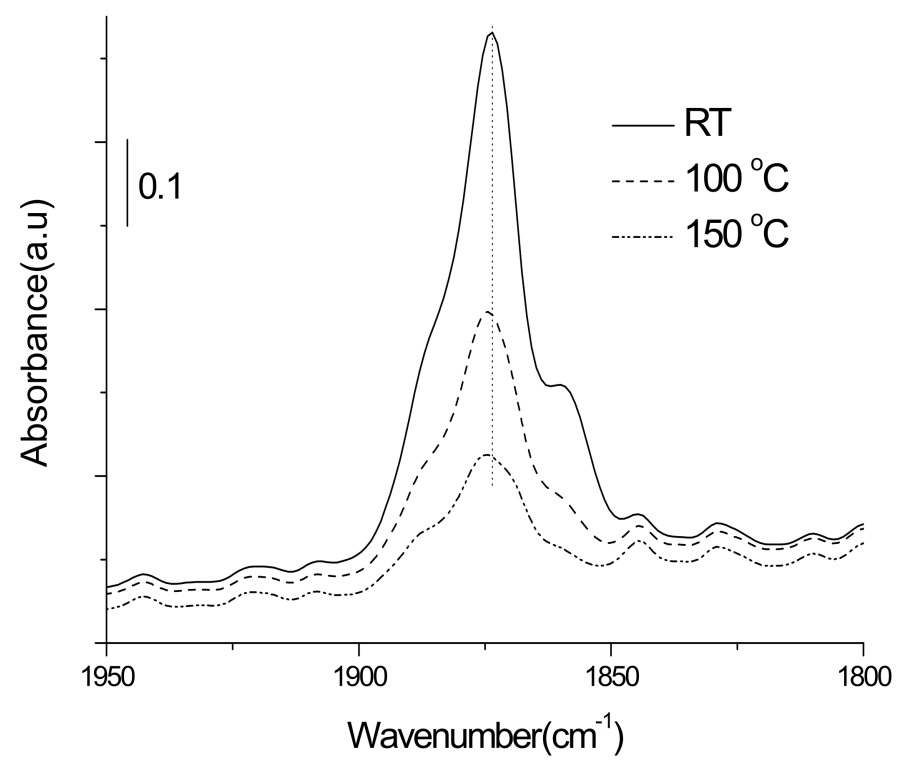

Figure 22. FT-IR spectra of desorption of adsorbed NO at elevated temperatures.

\subsubsection{Isotopic ${ }^{15} \mathrm{NO}$ Adsorption}

To investigate the adsorption/desorption behaviors in more detail, labeled ${ }^{15} \mathrm{NO}$ was employed following the pretreatment. The introduction of 10 torr ${ }^{15} \mathrm{NO}$ at room temperature afforded the spectrum shown in Figure 23 (curve a). Similar adsorption characteristics as those of ${ }^{14} \mathrm{NO}$ presented, and two main bands and a shoulder with narrow FWHM were observed at 1842, 1826, and $1853 \mathrm{~cm}^{-1}$. The positions of these bands showed about $30 \mathrm{~cm}^{-1}$ red shift compared with those of ${ }^{14} \mathrm{NO}$, which confirmed that these adsorbed bands were from the NO species. Three bands could be assigned to the mononitrosyl species, and no dinitrosyl species were observed, which is in correspondence with the results of ${ }^{14} \mathrm{NO}$ adsorption. An increase in the pressure or temperature under the $\mathrm{NO}$ atmosphere caused behaviors analogous to those of ${ }^{14} \mathrm{NO}$ adsorption/desorption (spectra not shown).

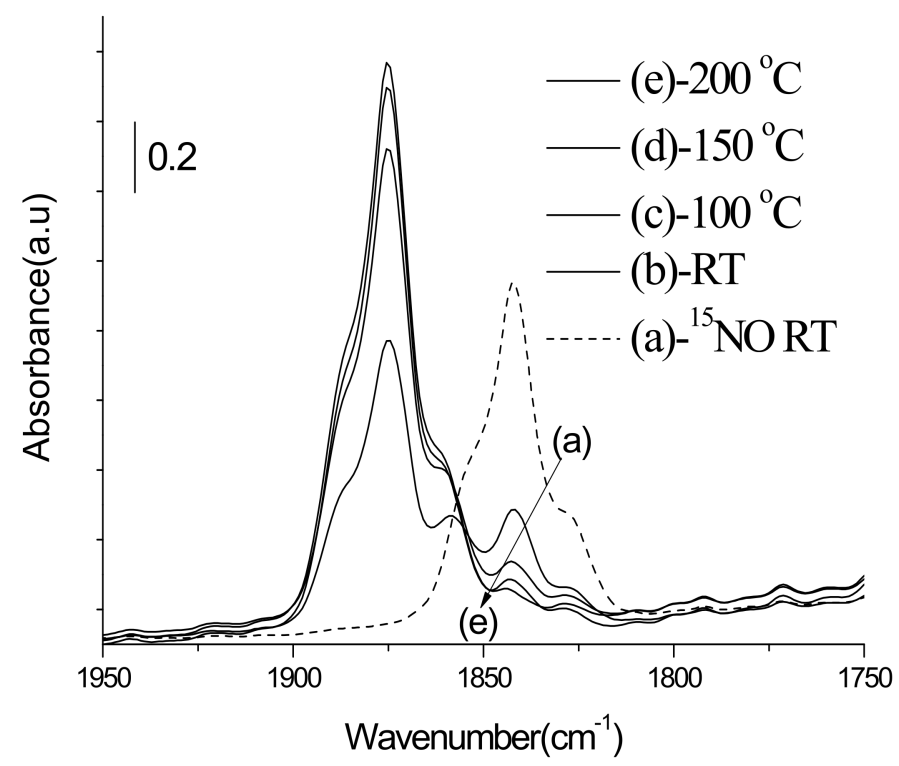

Figure 23. FT-IR spectra of 10 torr ${ }^{14} \mathrm{NO}$ adsorption at different temperatures on VSB-5 after preadsorption with labeled ${ }^{15} \mathrm{NO}$ at RT. 
Following the adsorption of ${ }^{15} \mathrm{NO}$ at ambient temperature and the following removal of gaseous ${ }^{15} \mathrm{NO}$ by evacuation, 10 torr ${ }^{14} \mathrm{NO}$ was introduced, and the adsorption was operated at a different temperature. The spectra were recorded at room temperature, as shown in curves b-e in Figure 23. Intense adsorption bands attributed to the characteristics of ${ }^{14} \mathrm{NO}$ were observed with the simultaneous decrease in isotopic ${ }^{15} \mathrm{NO}$ bands. The decrease in intensity of isotopic ${ }^{15} \mathrm{NO}$ after the introduction of ${ }^{14} \mathrm{NO}$ indicates that adsorbed isotopic ${ }^{15} \mathrm{NO}$ species were replaced by the gas phase of ${ }^{14} \mathrm{NO}$. The loss of intensity grew with the increase in temperature, and almost all the absorbed ${ }^{15} \mathrm{NO}$ species were replaced after the temperature rose to $200{ }^{\circ} \mathrm{C}$. At the same time, the intensities of adsorbed ${ }^{14} \mathrm{NO}$ species increased with temperature due to more sites being available at high temperature or being released by the dissociation of labeled ${ }^{15} \mathrm{NO}$.

However, the absorbed ${ }^{15} \mathrm{NO}$ species became stronger once the sample was heated to $150{ }^{\circ} \mathrm{C}$ under 10 torr of ${ }^{15} \mathrm{NO}$ atmosphere. The spectrum is shown in Figure 24 (curve a). ${ }^{14} \mathrm{NO}$ was then introduced after the gaseous isotopic ${ }^{15} \mathrm{NO}$ was removed by evacuation, and the spectra are shown in Figure 24 (curve b-f). Adsorption peaks from the ${ }^{14} \mathrm{NO}$ species emerged, and the intensity of ${ }^{15} \mathrm{NO}$ species simultaneously decreased a little. However, the intensity of ${ }^{15} \mathrm{NO}$ species was still stronger than that of ${ }^{14} \mathrm{NO}$ species adsorbed at room temperature, which is different from the result shown in Figure 24 (curve b). The intensities of ${ }^{14} \mathrm{NO}$ increased with the rise in temperature, and the maximum arrived by heating to $200{ }^{\circ} \mathrm{C}$, while at the same time, the intensities of ${ }^{15} \mathrm{NO}$ species decreased. However, obvious bands of ${ }^{15} \mathrm{NO}$ were still observed, even when the temperature was raised to $250{ }^{\circ} \mathrm{C}$. This further confirms that the species absorbed at raised temperatures was much more stable than those adsorbed at room temperature.

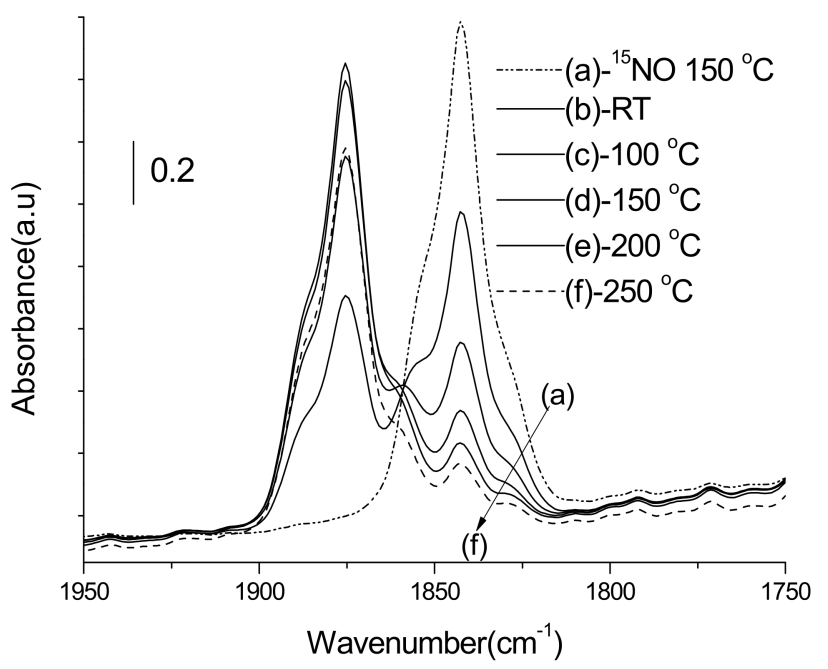

Figure 24. FT-IR spectra of 10 torr ${ }^{14} \mathrm{NO}$ adsorption at different temperatures on VSB-5 after preadsorption with labeled ${ }^{15} \mathrm{NO}$ at $150{ }^{\circ} \mathrm{C}$.

\subsubsection{CO Adsorption}

Figure 25 shows the in situ FT-IR spectra of adsorbed CO after procedure to those those of NO adsorption. One main peak at $2194 \mathrm{~cm}^{-1}$ was observed after the introduction of 10 torr $\mathrm{CO}$ at room temperature (curve at RT). Following the adsorption at room temperature for $60 \mathrm{~min}$, the sample was heated for $30 \mathrm{~min}$ at corresponding temperatures and then cooled down to room temperature. The deconvolution indicates that this main peak was composed of two peaks, at 2185 and $2195 \mathrm{~cm}^{-1}$, respectively, as shown in the inset. These peaks may be assigned to the $\mathrm{Ni}^{2+}-\mathrm{CO}$ species adsorbed at different $\mathrm{Ni}$ sites. No additional carbonyl peak was observed due to its weaker bond strength compared to that of the nitrosyl species. 


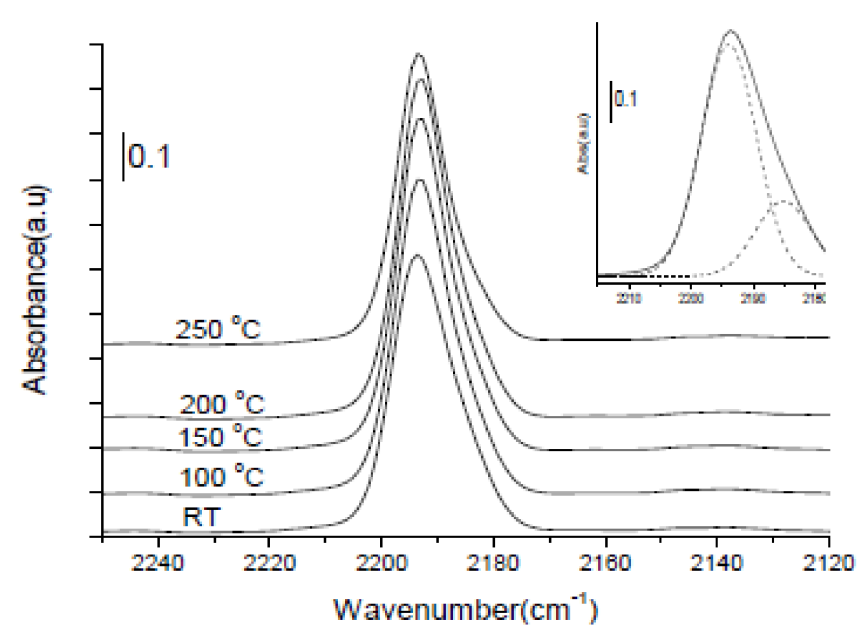

Figure 25. FT-IR spectra of $\mathrm{CO}$ adsorption at different temperatures for $30 \mathrm{~min}$. Inset shows the deconvolution spectrum at room temperature.

The intensities of main peaks increased with prolonged adsorption time, indicating that more $\mathrm{CO}$ was adsorbed during this period (spectrum was not shown). The integral intensity of the peaks increased with the rise of temperature and reached the maximum at $200{ }^{\circ} \mathrm{C}$. This indicates that $\mathrm{CO}$ might arrive at inaccessible sites at lower temperatures, which might be achievable during the heating process. Increasing the pressure or raising the temperature could promote the integral intensities and stability, which is in accordance with the behaviors of $\mathrm{NO}$ adsorption. This confirms that the heating process assists $\mathrm{CO}$ molecules to reach inaccessible sites at low temperatures. The maximum amount of $\mathrm{CO}$ adsorption was realized when the temperature was raised to $200{ }^{\circ} \mathrm{C}$, which is also similar to the case of NO. A sharp decrease in the intensity for species adsorbed at ambient temperature was observed after evacuation at room temperature, and complete removal of the adsorbed species was completed after evacuation at $150^{\circ} \mathrm{C}$, which demonstrates that the $\mathrm{CO}$ species adsorbed at room temperature were unstable and also weaker than the $\mathrm{NO}$ species. These results, together with the fact that the stretching frequency was higher than that of gaseous $\mathrm{CO}\left(2143 \mathrm{~cm}^{-1}\right)$, indicate that the VSB- 5 matrix had high electrophilicity and $\sigma$-carbonyls may be formed.

\subsubsection{Co-Adsorption of $\mathrm{NO}$ and $\mathrm{CO}$}

Figure 26 shows the spectra of co-adsorption experiments of $\mathrm{NO}$ and $\mathrm{CO}$. A total of 5 torr of $\mathrm{CO}$ and $\mathrm{NO}$, each, was added simultaneously to the catalyst disk following pretreatment. A strong peak at $1876 \mathrm{~cm}^{-1}$ and two shoulders attributed to the mononitrosyl species were observed, which is the same as those observed for $\mathrm{NO}$ adsorption in the absence of CO. Only a very weak band at $2196 \mathrm{~cm}^{-1}$, attributed to carbonyls, appeared, indicating the adsorption of $\mathrm{CO}$ was blocked by NO . The intensity of the $\mathrm{Ni}^{2+}-\mathrm{NO}$ species increased when the temperature was raised to $150^{\circ} \mathrm{C}$, while the intensity of $\mathrm{Ni}^{2+}$-CO species remained as before. This confirms that the adsorption of $\mathrm{NO}$ and $\mathrm{CO}$ was competitive, and the formed nitrosyl species were stronger than the carbonyls. 


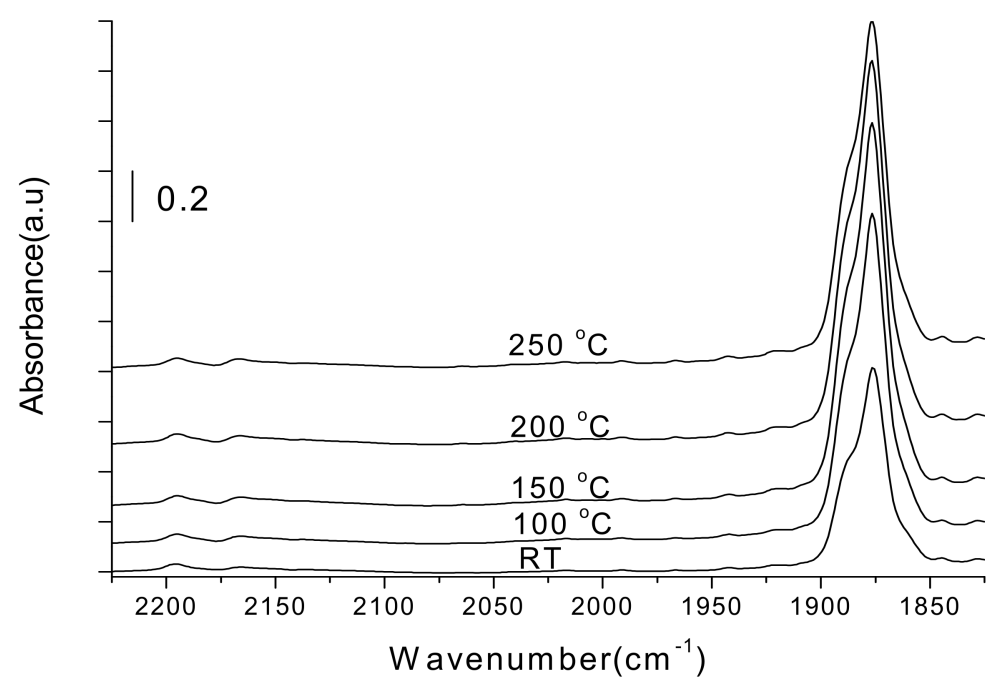

Figure 26. FT-IR spectra of coadsorption of NO \& CO (5 Torr each) at various temperatures.

To obtain more information, NO preadsorption was conducted firstly by introducing NO (10 Torr) and kept at ambient temperature for $30 \mathrm{~min}$. After removing gaseous $\mathrm{NO}$ by evacuation, CO (10 Torr) was introduced and liquid nitrogen was used to trap all the time. The results are shown in Figure 27.

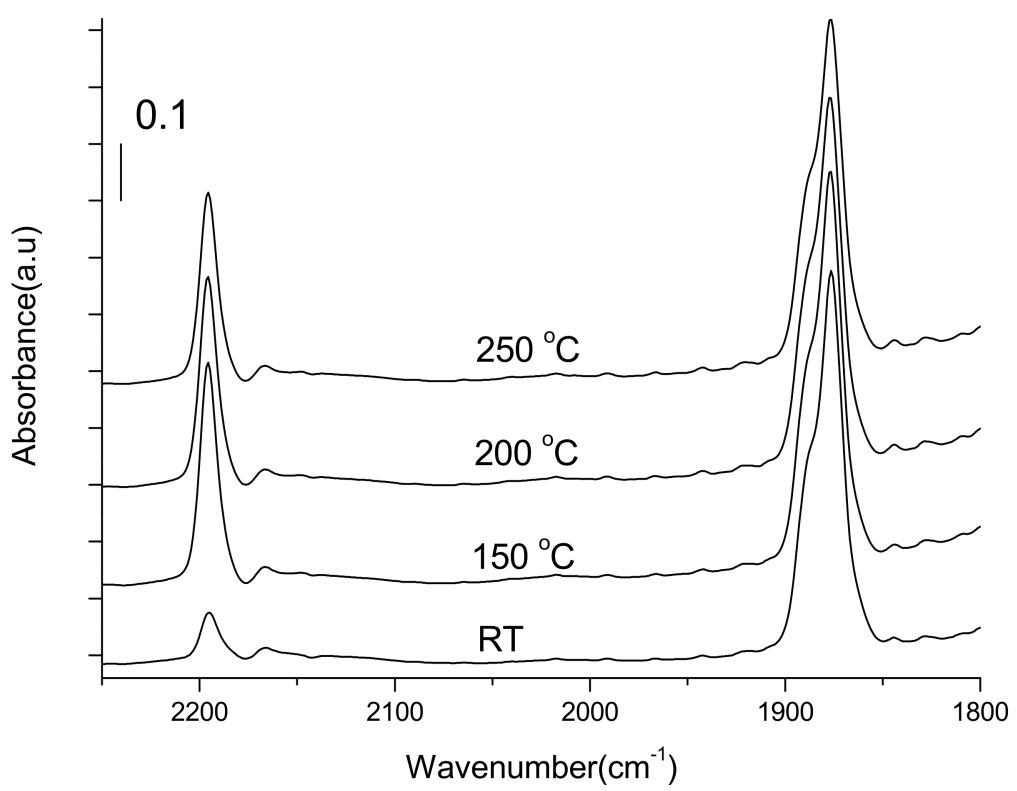

Figure 27. FT-IR spectra of coadsorption of NO and CO; CO (10 Torr) added after preadsorption of NO (10 Torr) at RT.

Carbonyl species were formed, and intense band at $2196 \mathrm{~cm}^{-1}$ was observed at room temperature. The intensities of carbonyls increased with rising temperatures, while the intensities of nitrosyls decreased at the mean time. The reappearance of the carbonyls demonstrated that $\mathrm{CO}$ adsorption could take place under low-equilibrium NO pressure conditions as liquid nitrogen acted as a cold trap $\left(\mathrm{P}_{\mathrm{NO}}=7 \times 10^{-2}\right.$ torr $)$. This further verifies that the adsorption of $\mathrm{NO}$ and $\mathrm{CO}$ was competitive and may take place at the same site. $\mathrm{NO}$ can be catalytically reduced by $\mathrm{CO}$ at high temperatures, based on the results of the online GC analysis in a closed gas-circulation system. A certain amount of $\mathrm{N}_{2}, \mathrm{~N}_{2} \mathrm{O}$, and $\mathrm{CO}_{2}$ was produced at $250{ }^{\circ} \mathrm{C}$. The intensities of adsorbed NO did not decrease much, even when the temperature was higher than $200^{\circ} \mathrm{C}$, suggesting that the adsorbed species might 
not be the direct reaction intermediate; however, the adsorbed compounds should act as reservoirs of the $\mathrm{NO}-\mathrm{CO}$ reaction.

In this study, VSB-5 was first used as an active component for the adsorption of $\mathrm{NO}$ and/or $\mathrm{CO}$ and demonstrated catalytic activity for reduction of $\mathrm{NO}$ by $\mathrm{CO}$. A large amount of NO and/or CO can be adsorbed in the micropores of VSB-, and novel adsorption behaviors were first observed. Strong and sharp adsorption bands of mononitrosyl species were observed at ambient temperature. An increase in temperature might produce more uncoordinated sites that were inaccessible at low temperatures for adsorption; this resulted in the increase in the quantity and intensity of adsorbed species. Species adsorbed at high temperatures became more stable than those adsorbed at ambient temperature, and they are difficult to be replaced by the labeled gas. The adsorption of $\mathrm{CO}$ and NO is competitive, and the adsorption of $\mathrm{CO}$ may be blocked by $\mathrm{NO}$ since the latter has stronger bond strength.

\section{Experimental}

\subsection{Catalyst Preparation}

The K-titanate nanobelt $\left(\mathrm{K}_{2} \mathrm{Ti}_{8} \mathrm{O}_{17}: \mathrm{KTN}\right)$ was prepared using hydrothermal treatment, with $\mathrm{TiO}_{2}$ and $\mathrm{KOH}$ as starting materials. In XRD measurements of the obtained $\mathrm{KTN}$, all reflection peaks were assigned to a monoclinic phase of $\mathrm{K}_{2} \mathrm{Ti}_{8} \mathrm{O}_{17}$ (JCPDS No. 84-2057). Nanobelts several micrometers in length and tens of nanometers in width with bending and twisting features were observed using TEM. Specifically, $3 \mathrm{~g}$ of $\mathrm{TiO}_{2}$ was added to $100 \mathrm{~mL}$ of $10 \mathrm{~mol} / \mathrm{L} \mathrm{KOH}$ aqueous solution and stirred for $30 \mathrm{~min}$. The suspension was transferred to the autoclave, sealed, and heated to $130{ }^{\circ} \mathrm{C}$ for 4 days. The white solid product was collected by filtration, washed with deionized water several times, and finally dried at $100^{\circ} \mathrm{C}$ overnight.

Alkali metal nitrates of various kinds (designated as $\mathrm{MNO}_{3}: \mathrm{M}=\mathrm{Li}, \mathrm{Na}, \mathrm{K}, \mathrm{Rb}$, and Cs) and $1.5 \mathrm{wt} \% \mathrm{Pt}$ were dispersed onto the KTN support using a conventional impregnation method. The impregnation amounts of $\mathrm{MNO}_{3}$ were, respectively, $13(\mathrm{M}=\mathrm{Li}), 17(\mathrm{Na})$, $20(\mathrm{~K}), 27(\mathrm{Rb})$, and $33 \mathrm{wt} \%(\mathrm{Cs})$, which corresponded to $2 \mathrm{mmol} / \mathrm{g}$ on catalysts. Mixtures of the KTN and aqueous solutions of $\mathrm{H}_{2} \mathrm{PtCl}_{6}$ and $\mathrm{MNO}_{3}$ were put into an oven at $70{ }^{\circ} \mathrm{C}$ until complete evaporation of water was achieved, with subsequent calcination at $350{ }^{\circ} \mathrm{C}$ for $2 \mathrm{~h}$. The catalysts were designated as $\mathrm{Pt}-\mathrm{xxMNO} / \mathrm{KTN}$, where $\mathrm{xx}$ signifies the weight percent of $\mathrm{MNO}_{3}$.

Nickel phosphate VSB-5 (Versailles-Santa Barbara) catalysts were prepared by the following preparation conditions: in the cases of VSB-5(TEA), Co-VSB-5(TEA), and Fe-VSB5(TEA), the molar ratios of Ni: M: P: TEA: $\mathrm{H}_{2} \mathrm{O}=(1-\mathrm{x}): \mathrm{x}: 0.92: 3: 200$ with $\mathrm{pH}=10(\mathrm{x}=0.2$ for $\mathrm{Co}$ and $\mathrm{Fe}$ ), and in the case of VSB-5( $\left(\mathrm{NH}_{3}\right)$, the molar ratio of $\mathrm{Ni}: \mathrm{P}: \mathrm{H}_{2} \mathrm{O}=1: 0.63: 100$ with $\mathrm{NH}_{3}$ aq adjusting $\mathrm{pH}=7.7$. After stirring for $1 \mathrm{hr}$ at room temperature, the solution was put into an autoclave and kept at $442 \mathrm{~K}$ for 4 days. $\mathrm{NaOH}$ treatment was carried out following calcination of dried samples at $623 \mathrm{~K}$ by stirring in $1 \mathrm{M}$ aq. $\mathrm{NaOH}$ solution $(\mathrm{pH}=13.2)$ for $6 \mathrm{~h}$.

\subsection{Catalyst Characterization}

Adsorption isotherms were taken by a Belsorp MAX apparatus at $77 \mathrm{~K}\left(\mathrm{~N}_{2}, \mathrm{CO}\right)$, $293 \mathrm{~K}(\mathrm{NO})$, and $423 \mathrm{~K}$ (NO). The samples were thoroughly evacuated at $627 \mathrm{~K}$ for $24-36 \mathrm{~h}$ before the measurement. NO-CO reaction (10 Torr each) was carried out with a glass-made closed gas-circulation system with online analysis by G.C.

The XRD patterns were recorded using a diffractometer (MultiFlex; Rigaku Corp.) with a $\mathrm{Cu} \mathrm{K1}$ X-ray source $(50 \mathrm{kV}, 30 \mathrm{~mA})$. Then, X-ray photoelectron spectroscopy (XPS) was conducted using a spectrometer (JPM-9010 MC, JEOL). The XPS apparatus had a preparation chamber in which a sample could be heated in situ and reduced by hydrogen (in situ hydrogen reduction). The $\mathrm{C} 1 \mathrm{~s}(284.3 \mathrm{eV})$ peak was used as the standard reference for binding energies.

The IR spectra of adsorbed species were measured as follows: self-standing pellets (50 mg) were pressed and treated in situ in the IR cell. The FT-IR spectra were recorded at 
room temperature on a JASCO FT/IR 660 instrument equipped with an MCT detector at a resolution of $4 \mathrm{~cm}^{-1}$ with 512 scans. Before adsorption, NO was further purified by passing it through a liquid-nitrogen cold trap and additional fraction distillation. The wafer was heated at different temperatures under vacuum for $1 \mathrm{~h}$ as pretreatment. The intensity of the adsorbed species at room temperature increased with the pretreatment temperature, and the intensity pretreated at $250{ }^{\circ} \mathrm{C}$ was about 5 times that of the intensity evacuated at $150{ }^{\circ} \mathrm{C}$. The pretreatment temperature was set as $250^{\circ} \mathrm{C}$, considering the thermal stability and the removal of the species blocked in the micropores. The adsorption/desorption time was set at $30 \mathrm{~min}$ for all the FT-IR experiments

For TPD measurement, $300 \mathrm{mg}$ VSB-5 powder was put into a quartz tube. As a pretreatment, the sample was heated to $250{ }^{\circ} \mathrm{C}$ with a ramp of $5{ }^{\circ} \mathrm{C} \mathrm{min}$ min $^{-1}$ and kept for $1 \mathrm{~h}$ under He flow $\left(50 \mathrm{~mL} \mathrm{~min}^{-1}\right)$. The adsorption of $\mathrm{NO}(0.1 \mathrm{vol} \% \mathrm{NO}$ balanced with $\mathrm{He}$ ) was operated at room temperature or at $150{ }^{\circ} \mathrm{C}$ for $30 \mathrm{~min}$. The amount of adsorbed NO was calculated from the D-value between the input and output. The following TPD

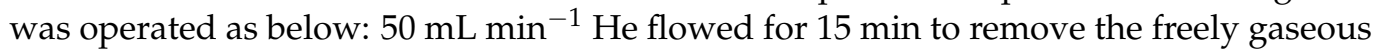
$\mathrm{NO}$; then, the temperature was raised $\left(5^{\circ} \mathrm{C} \mathrm{min}^{-1}\right)$ under He flow $\left(50 \mathrm{~mL} \mathrm{~min}{ }^{-1}\right)$; the out-coming species were recorded by quadruple mass spectrometer (QME200, PFEIFFER).

\subsection{Procedure for NOx Storage/Reduction}

The catalytic tests were performed on a fixed-bed gas-flow system equipped with a pulse gas-feed system, with an online quadruple mass spectrometer (QMS) as detector. Before every catalytic test, the sample was reduced by $80 \mathrm{~mL} / \mathrm{min} 8 \% \mathrm{H}_{2} / \mathrm{He}$ flow in the quartz tube reactor from room temperature to $350{ }^{\circ} \mathrm{C}$, with a ramp rate of $10^{\circ} \mathrm{C} / \mathrm{min}$, and maintained at $350^{\circ} \mathrm{C}$ for $30 \mathrm{~min}$. During this reduction procedure, outlet gas was analyzed by a QMS and used for temperature program reduction (TPR) profiles. The signal of He was used as reference to calculate the relative signal intensity of other gases. For example, the relative signal intensity of $\mathrm{H}_{2}$ was calculated as $\mathrm{I}_{\mathrm{m} / \mathrm{e}}=2 / \mathrm{I}_{\mathrm{m} / \mathrm{e}}=4$. For the isothermal $\mathrm{NO}_{x}$ storage test, $80 \mathrm{~mL} / \mathrm{min} 930 \mathrm{ppm} \mathrm{NO} / 7 \% \mathrm{O}_{2} / \mathrm{He}$ was flowed through $100 \mathrm{mg}$ catalyst at $350{ }^{\circ} \mathrm{C}$, and the outlet gas was analyzed by QMS. After the adsorption, the gas flow was switched to He for 15 min flushing. Then, the $\mathrm{NO}_{\mathrm{x}}$ storage catalyst was reduced by $4 \%$ $\mathrm{H}_{2}$ / He at the same temperature, and the outlet gas was recorded by QMS. After flushing with He for $15 \mathrm{~min}$, the processes of NOx storage and reduction were repeated, and the data obtained from the second time was used for analysis.

For the lean-rich cycling test, $50 \mathrm{mg}$ of catalyst was used. The lean-rich cycles $(6 \mathrm{~min}$ of $930 \mathrm{ppm} \mathrm{NO} / 7 \% \mathrm{O}_{2} / \mathrm{He}$ and $4 \mathrm{~min}$ of $4 \% \mathrm{H}_{2} / \mathrm{He}$ with $160 \mathrm{~mL} / \mathrm{min}$ flow rate) were adopted to check the kinetic property and stability of the catalysts. To simulate the gas composition of mobile exhaust during rich condition, $930 \mathrm{ppm} \mathrm{NO} / 4 \% \mathrm{H}_{2} / \mathrm{He}$ was also used as reductant for lean-rich cycling test. In this case, $160 \mathrm{~mL} / \mathrm{min} 930 \mathrm{ppm} \mathrm{NO} / 7 \%$ $\mathrm{O}_{2} / \mathrm{He}$ flow was flowed through $50 \mathrm{mg}$ catalyst for $3 \mathrm{~min}$ and then switched to $160 \mathrm{~mL} / \mathrm{min}$ $930 \mathrm{ppm} \mathrm{NO} / 4 \% \mathrm{H}_{2} / \mathrm{He}$ flow for $30 \mathrm{sec}$.

The hydrogenation of $\mathrm{CO}$ was conducted in a closed gas-circulation system with a liquid nitrogen cold trap, along with the circulation loop, which simplified the product analysis and which prevented secondary reactions, such as olefin hydrogenation and water-gas shift reaction. The reaction products were analyzed using online gas chromatography (TCD and FID). The catalyst was reduced by 200 torr of $\mathrm{H}_{2}$ at $573 \mathrm{~K}$ for $5 \mathrm{~h}$ before reaction. The $\mathrm{CO}-\mathrm{H}_{2}$ reaction was conducted at $473 \mathrm{~K}$ with $1: 2$ ratios of $\mathrm{CO}$ and $\mathrm{H}_{2}$ (total pressure $=150$ torr).

\section{Conclusions and Perspective}

Since the introduction of the NOx storage-reduction (NSR) concept in 1995 by Toyota, many studies have been carried out to obtain a better understanding of the NSR mechanism and to obtain more efficient materials and improved engine control for the NOx abatement. In the present article, we first addressed the overview of the development of the NSR catalysts, followed by the application of nanostructured materials for NSR processes. In the 


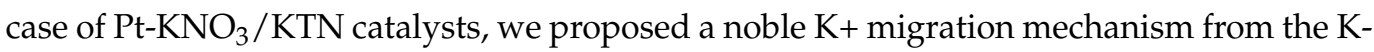
rich surface layer to the bulk KTN, which achieves a fast response of storage and reduction processes with high capacity. We also applied microporous VSB-5 as the NO storage nanospace, which showed activated adsorption and desorption behavior and advantages for NSR processes. We also tried to substitute the $\mathrm{Ni}^{2+}$ ion of the VSB- 5 framework with $\mathrm{CO}^{2+}$ and $\mathrm{Cu}^{2+}$ ions, which caused a drastic increase in the NSR ability, with one order of magnitude higher NSR capacity. However, it is desirable to discover more stable and affordable materials for effective NSR catalysts in the near future.

In conclusion, we summarize the important future studies for NSR catalysis as follows:

(1) Although there is a wide general agreement concerning the mechanism of NSR processes, diversified and sometimes contradictory results have also been reported, mainly due to different experimental conditions used by the various researchers, such as different lean and regeneration periods, different reducing gases, different catalyst preparation and pretreatment, and different mass- and heat-transfer conditions. NOx storage is a sequential process (initially, nitrite and eventually, nitrate formation), which still does not clearly state the nature of the Ba species, nor does it account for the NOx slip during the storage process. The NOx reduction mechanism and the product selectivity under rich conditions are dependent on the reductants. $\mathrm{NH}_{3}$, which has recently been considered to be an intermediate reductant, has not been universally observed and accepted by researchers.

(2) The noble metal $\mathrm{Pt}$ is widely used by researchers for the oxidation of $\mathrm{NO}$ and the subsequent reduction of stored NOx. However, the nature of the Pt particles, such as the loading, dispersion, size and the morphology, and metal-support interaction influencing the catalytic activity are still the subject of debate. There is still no conclusive understanding of the optimum loading, shape, and dispersion of Pt particles for the best catalytic activity. Investigations have been carried out with other noble metals, such as Pd and Rh. Furthermore, the potential of metal alloys needs to be explored.

(3) The storage component best investigated and commonly used is Ba; however, the nature of the storage component is still not clear. According to some researchers, $\mathrm{BaCO}_{3}$ is the dominant storage component under real conditions, whereas others claim that $\mathrm{BaO}$ is a better potential storage component than $\mathrm{BaCO}_{3}$. Researchers have revealed that the proximity of $\mathrm{Ba}$ and the noble metal is important in the storage process; however, systematic investigations are still lacking regarding this aspect. Overall, it is accepted that $\mathrm{BaAl}_{2} \mathrm{O}_{4}$ is formed at higher temperatures during the NSR operation, although the exact role of $\mathrm{BaAl}_{2} \mathrm{O}_{4}$ is unknown. Storage materials, other than $\mathrm{Ba}$, such as $\mathrm{K}, \mathrm{Mg}$, and $\mathrm{Ca}$ showed promising performance in the storage step, as well as less sulfur poisoning, which needs to be explored more profoundly.

(4) Besides stabilizing the dispersed noble metal particles, the support material can also affect the oxidation state of the noble metal and the spillover process, which has an effect on the oxidation, storage, and regeneration (reduction) steps, and thus, the overall performance of the NSR catalyst. For Ba-based lean traps, NOx storage capacity seems to follow the basicity of the oxide support, while the rate of NOx reduction tends to decrease with stronger basicity of the support. An open question is the role of the support in the spillover processes occurring in the NSR system. Furthermore, for a deeper understanding of the surface processes during NSR, the structure and chemistry of the interfaces of the support with catalytic (noble metals) and storage components (alkali and alkaline earth metals) need to be investigated more thoroughly, particularly under dynamic conditions.

Funding: This research received no external funding.

Data Availability Statement: Not applicable.

Conflicts of Interest: The authors declare no conflict of interest. 


\section{References}

1. Roy, S.; Baiker, A. NOx Storage-Reduction Catalysis: From Mechanism and Materials Properties to Storage-Reduction Performance. Chem. Rev. 2009, 109, 4054-4091. [CrossRef]

2. Centi, G.; Arena, G.E.; Perathoner, S. Nanostructured Catalysts for NOx Storage-Reduction and $\mathrm{N}_{2} \mathrm{O}$ decomposition. J. Catal. 2003, 216, 443-454. [CrossRef]

3. Kaspar, J.; Fornasiero, N.P.; Hicky, N. Automotive Catalytic Converters: Current Status and Some Perspectives. Catal. Today 2003, 77, 419-449. [CrossRef]

4. Takahashi, N.; Shinjoh, H.; Suzuki, T.; Yamazaki, K.; Yokota, K.; Suzuki, H.; Miyoshi, N.; Matsumoto, H.; Tanizawa, T.; Tanaka, T.; et al. The New Concept 3-way Catalyst for Automotive Lean-burn Engine: NOx Storage and Reduction Cataltst. Catal. Today 1996, 27, 63-69. [CrossRef]

5. Matsumoto, S. Denox catalyst for automotive lean-burn engine. Catal. Today 1996, 29, 43-45. [CrossRef]

6. Matsumoto, S.; Ikeda, Y.; Suzuki, H.; Ogai, M.; Miyoshi, N. NOx Storage-Reduction Catalyst for Automotive Exhaust with Improved Torerance against Sulfur Poisoning. Appl. Catal. B Environ. 2000, 25, 115-124. [CrossRef]

7. Yamazaki, K.; Suzuki, T.; Takahashi, N.; Yokota, K.; Sugiura, M. Effect of the Addition of Transition $\mathrm{Metals}$ to Pt/Ba/ $\mathrm{Al}_{2} \mathrm{O}_{3}$ Catalyst on the NOx Storage-Reduction Catalysis under Oxidizing Conditions in the Presence of SO 2. Appl. Catal. B Environ. 2001, 30, 459-468. [CrossRef]

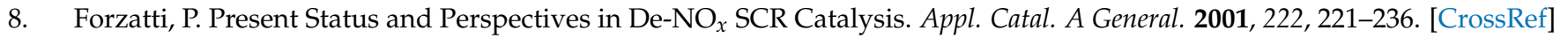

9. Busca, G.; Lietti, L.; Ramis, G.; Berti, F. Chemical and mechanistic aspects of the selective catalytic reduction of $\mathrm{NO}_{\mathrm{x}}$ by ammonia over oxide catalysts: A review. Appl. Catal. B Environ. 1998, 18, 1-36. [CrossRef]

10. Iwamoto, M.; Yahiro, H.; Shundo, S.; Yu-u, Y.; Mizuno, N. Influence of Sulfur Dioxide on Catalytic Removal of Nitric Oxide over Copper Ion-Exchanged ZSM-5 Zeolite. Appl. Catal. 1991, 69, L15-L19. [CrossRef]

11. Theinnoi, K.; Sitshebo, S.; Houel, V.; Rajaram, R.R.; Tsolakis, A. Hydrogen Promotion of Low-Temperature Passive HydrocarbonSelective Catalytic Reduction (SCR) over a Silver Catalyst. Energy Fuels 2008, 22, 4109-4114. [CrossRef]

12. Burch, R.; Breen, J.P.; Hill, C.J.; Krutzsch, B.; Konrad, B.; Jobson, E.; Cider, L.; Eranen, K.; Klingstedt, F.; Lindfors, L.-E. Exceptional Activity for $\mathrm{NO}_{\mathrm{x}}$ Reduction at Low Temperatures Using Combinations of Hydrogen and Higher Hydrocarbons on $\mathrm{Ag}_{\mathrm{g}} / \mathrm{Al}_{2} \mathrm{O}_{3}$ Catalysts. Top. Catal. 2004, 30-31, 19-25. [CrossRef]

13. Frola, F.; Manzoli, M.; Prinetto, F.; Ghiotti, G. Pt-Ba/ $\mathrm{Al}_{2} \mathrm{O}_{3}$ NSR Catalysts at Different Ba Loading: Characterization of Morphological, Structural, and Surface Properties. J. Phys. Chem. C 2008, 112, 12869-12878. [CrossRef]

14. Happel, H.; Desikusumastuti, A.; Sobota, M.; Laurin, M.; Libuda, J. Impact of Sulfur Poisoning on the Uptake of a NOx Storage Reduction (NSR) Model Catalyst. J. Phys. Chem. C 2010, 114, 4568-4575. [CrossRef]

15. Lietti, L.; Forzatti, P.; Nova, I.; Tronconi, E. $\mathrm{NO}_{x}$ Storage Reduction over Pt@Ba $/ \gamma-\mathrm{Al}_{2} \mathrm{O}_{3}$. J. Catal. 2001, 204, 175-191. [CrossRef]

16. Rankovic, N.; Nicolle, A.; Costa, P.D. Detailed Kinetic Modeling Study of NOx Oxidation and Storage and Their Interactions over $\mathrm{Pt} / \mathrm{Ba} / \mathrm{Al}_{2} \mathrm{O}_{3}$ Monolith Catalysts. J. Phys. Chem. C 2010, 114, 7102-7111. [CrossRef]

17. Lesage, T.; Saussey, J.; Malo, S.; Hervieu, M.; Hedouin, C.; Blanchard, G.; Daturi, M. Operando FTIR study of $\mathrm{NO}_{\mathrm{x}}$ storage over a $\mathrm{Pt} / \mathrm{K} / \mathrm{Mn} / \mathrm{Al}_{2} \mathrm{O}_{3}-\mathrm{CeO}_{2}$ catalyst. Appl. Catal. B Environ. 2007, 72, 166-177. [CrossRef]

18. Liu, Y.; Meng, M.; Zou, X.; Li, Z.; Zha, Y. In Situ DRIFTS Investigation on the NOx Storage $\mathrm{Mechanisms} \mathrm{over} \mathrm{Pt/K/TiO}_{2}-\mathrm{ZrO} 2$. Catalyst Catal. Commun. 2008, 10, 173-177. [CrossRef]

19. de Lucas, A.; Caravaca, A.; Sanchez, P.; Dorado, F.; Valverde, J.L. A New Improvement of Catalysis by Solid-State Electrochemistry:An Electrochemically Assisted $\mathrm{NO}_{x}$ Storage/Reduction catalyst. J. Catal. 2008, 259, 54-65.

20. Yamamoto, K.; Kikuchi, R.; Takeguchi, T.; Eguchi, K. Development of NO Sorbents Tolerant to Sulfur Oxides. J. Catal. 2006, 238, 449-457. [CrossRef]

21. Wang, Q.; Guo, Z.; Chung, J.S. Molecular $\mathrm{NO}_{2}$ Induced $\mathrm{K}_{2} \mathrm{Ti}_{2} \mathrm{O}_{5}-\mathrm{K}_{2} \mathrm{Ti}_{6} \mathrm{O}_{13}$ Structure Switching in the Dry Gas Phase: Lattice Potassium Reactivity. Chem. Commun. 2009, 35, 5284-5286. [CrossRef]

22. Wang, Q.; Sohn, J.H.; Chung, J.S. Thermally Stable Pt $/ \mathrm{K}_{2} \mathrm{Ti}_{2} \mathrm{O}_{5}$ as High-Temperature $\mathrm{NO}_{x}$ Storage and Reduction Catalyst. Appl. Catal. B Environ. 2009, 89, 97-103. [CrossRef]

23. Sun, X.; Li, Y. Synthesis and Characterization of Ion-Exchangeable Titanate Nanotubes. Chem. Europian. J. 2003, 9, $2229-2238$. [CrossRef] [PubMed]

24. Lan, Y.; Gao, X.; Zhu, H.; Zheng, Z.; Yan, T.; Wu, F.; Ringer, S.; Song, D. Titanate Nanotubes and Nanorods Prepared from Rutile Powder. Adv. Funct. Mater. 2005, 15, 1310-1318. [CrossRef]

25. Tsai, C.; Teng, H. Nanotube Formation from a Sodium Titanate Powder via Low-Temperature Acid Treatment. Langmuir 2008, 24, 3434-3438. [CrossRef]

26. Bavykin, D.V.; Friedrich, J.M.; Lapkin, A.A.; Walsh, F.C. Stability of Aqueous Suspensions of Titanate Nanotubes. Chem. Mater. 2006, 18, 1124-11129. [CrossRef]

27. Sun, X.; Chen, X.; Li, Y. Large-Scale Synthesis of Sodium and Potassium Titanate Nanobelts. Inorg. Chem. 2002, 41, 4996-4998. [CrossRef]

28. Idakiev, V.; Yuan, Z.-Y.; Tabakova, T.; Su, B.-L. Titanium Oxide Nanotubes as Supports of Nano-sized Gold Catalysts for Low Temperature Water-gas Shift Reaction. Appl. Catal. A Gen. 2005, 281, 149-155. [CrossRef]

29. Torrente-Murciano, L.; Lapkin, A.A.; Bavykin, D.V.; Walsh, F.C.; Wilson, K. Highly selective Pd/titanate nanotube catalysts for the double-bond migration reaction. J. Catal. 2007, 245, 272. [CrossRef] 
30. Ntho, T.A.; Anderson, J.A.; Scurrell, M.S. CO Oxidation over Titanate Nanotube Supported Au: Deactivation due to Bicarbonate. J. Catal. 2009, 261, 94. [CrossRef]

31. Shen, W.; Nitta, A.; Chen, Z.; Eda, T.; Yoshida, A.; Naito, S. $\mathrm{NO}_{\mathrm{x}}$ storage and reduction over potassium titanate nnanobelt-based catalyst with high storage capacity. J. Catal. 2011, 280, 161-167. [CrossRef]

32. Yoshida, A.; Shen, W.; Eda, T.; Watanabe, R.; Ito, T.; Naito, S. NOx storage/reduction over alkali-metal-nitrate impregnated titanate nanobelt catalysts and investigation of alkali metal cation migration using XPS. Catal. Today 2012, 184, 78-82. [CrossRef]

33. Gopalakrishnan, R.; Bartholomew, C.H. Zeolite Selective Catalytic Reduction Catalysts for $\mathrm{NO}_{\mathrm{x}}$ Removal from Nuclear Waste Processing Plants. ACS Symp. Ser. 1995, 587, 56-70.

34. Shelef, M. Selective catalytic reduction of NOx with N-free reductants. Chem. Rev. 1995, 95, 209-225. [CrossRef]

35. Li, Y.; Armor, J.N. Selective catalytic reduction of NOx with methane over metal exchange zeolites. Appl. Catal. B Environ. 1993, 2 , 239-256. [CrossRef]

36. Korhonen, S.T.; Fickel, D.W.; Lobo, R.F.; Weckhuysen, B.M.; Beale, A.M. Isolated Cu2+ ions: Active sites for selective catalytic reduction of NO. Chem. Commun. 2011, 47, 800-802. [CrossRef] [PubMed]

37. Xue, J.; Wang, X.; Qi, G.; Wang, J.; Shen, M.; Li, W. Characterization of copper species over Cu/SAPO-34 in selective catalytic reduction of NOx with ammonia: Relationships between active $\mathrm{Cu}$ sites and de-NOx performance at low temperature. J. Catal. 2013, 297, 56-64. [CrossRef]

38. Burch, R.; Scire, R. An investigation of the mechanism of the selective catalytic reduction of NO on various metal/ZSM-5 catalysts: Reactions of $\mathrm{H}_{2} / \mathrm{NO}$ mixtures. Catal. Lett. 1994, 27, 177-186. [CrossRef]

39. Yu, Q.; Richter, M.; Kong, F.; Li, L.; Wu, G.; Guan, N. Selective catalytic reduction of NO by hydrogen over Pt/ZSM-35. Catal. Today 2010, 158, 452-458. [CrossRef]

40. Ravata, V.; Aghalayam, P. Effect of Noble Metals Deposition on the Catalytic Activity of MAPO-5 Catalysts for the reduction of NO by CO. Appl. Catal. A Gen. 2010, 389, 9-18. [CrossRef]

41. Mihaylov, M.; Hadjiivanov, K. FTIR Study of CO and NO Adsorption and Coadsorption on Ni-ZSM-5 and Ni/SiO 2 . Langmuir 2002, 18, 4376-4383. [CrossRef]

42. Mosqueda-Jiménez, B.I.; Jentys, A.; Seshan, K.; Lercher, J.A. Structure-activity Relationship for Ni-containing Zeolites during NO reduction 1. Influence of Acid Sites. J. Catal. 2003, 218, 348-353. [CrossRef]

43. Mihaylova, A.; Hadjiivanov, K.; Dzwigaj, S.; Che, M. Remarkable Effect of the Preparation Technique on the State of Cobalt Ions Zeolites Evidenced by FTIR Spectroscopy of Adsorbed CO and NO, TPR and XRD. J. Phys. Chem. B 2006, 110, 19530-19536. [CrossRef] [PubMed]

44. Hadjiivanov, K.; Kno1zinger, H.; Mihaylov, M. FTIR study of CO adsorption on Ni-ZSM-5. J. Phys. Chem. B 2002, 106, 2618-2624. [CrossRef]

45. Gianotti, E.; Vishnuvarthan, M.; Berlier, G.; Marchese, L.; Coluccia, S. FT-IR Study of Cobalt Containing Aluminophosphates with Chabasite Like Structure by Using CO and NO as Molecular Probes. Catal. Lett. 2009, 133, 27-32. [CrossRef]

46. Iwasaki, M.; Shinjoh, H. NO Evolution Reaction with $\mathrm{NO}_{2}$ Adsorption over Fe/ZSM-5: In situ FT/IR Observation and Relationships with Fe Sites. J. Catal. 2010, 273, 29-38. [CrossRef]

47. Chen, Z.; Zhou, D.; Gao, T.; Shen, W.; Dong, X.; Naito, S. Unusual adsorption and drsorption behaviors of NO and CO on nanoporous nickel phosphate VSB-5: In situ FT-IR and XRD study. Catal. Today 2015, 258, 199-204. [CrossRef] 